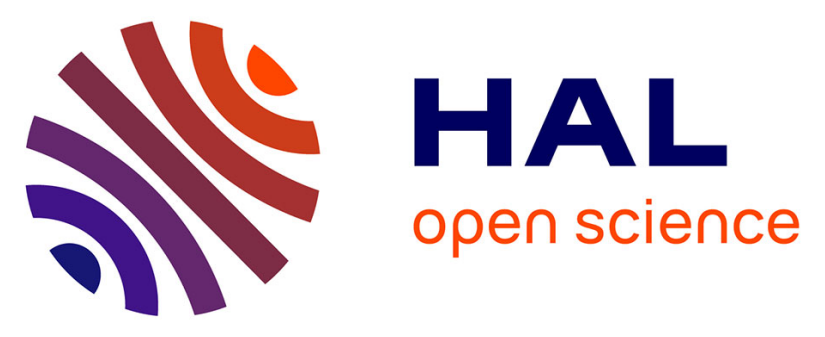

\title{
(Special Issue - Wireless Manufacturing) A Review of Localization Algorithms for Distributed Wireless Sensor Networks in Manufacturing
}

Fiorenzo Franceschini, Maurizio Galetto, Domenico Maisano, Luca

Mastrogiacomo

\section{To cite this version:}

Fiorenzo Franceschini, Maurizio Galetto, Domenico Maisano, Luca Mastrogiacomo. (Special Issue Wireless Manufacturing) A Review of Localization Algorithms for Distributed Wireless Sensor Networks in Manufacturing. International Journal of Computer Integrated Manufacturing, 2009, 22 (07), pp.698-716. 10.1080/09511920601182217 . hal-00513388

\section{HAL Id: hal-00513388 \\ https://hal.science/hal-00513388}

Submitted on 1 Sep 2010

HAL is a multi-disciplinary open access archive for the deposit and dissemination of scientific research documents, whether they are published or not. The documents may come from teaching and research institutions in France or abroad, or from public or private research centers.
L'archive ouverte pluridisciplinaire HAL, est destinée au dépôt et à la diffusion de documents scientifiques de niveau recherche, publiés ou non, émanant des établissements d'enseignement et de recherche français ou étrangers, des laboratoires publics ou privés. 


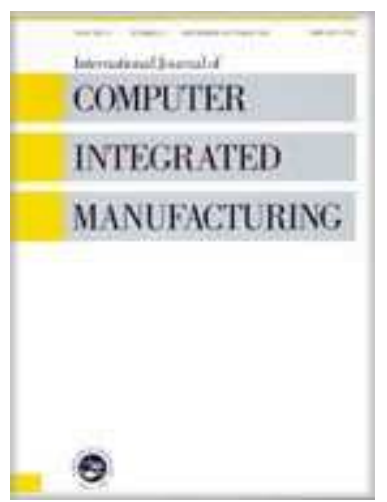

\section{(Special Issue - Wireless Manufacturing) A Review of Localization Algorithms for Distributed Wireless Sensor Networks in Manufacturing}

\begin{tabular}{|r|l|}
\hline Journal: & International Journal of Computer Integrated Manufacturing \\
\hline Manuscript ID: & TCIM-2006-IJCIM-0057.R2 \\
\hline Manuscript Type: & Original Manuscript \\
\hline Author: & 19-Dec-2006 \\
\hline Complete List of Authors: & $\begin{array}{l}\text { Franceschini, Fiorenzo; Politecnico di Torino, Dip.to Sistemi di Prod } \\
\text { ed Econ dell'Azienda } \\
\text { Galetto, Maurizio; Politecnico di Torino, Dip.to Sistemi di Prod ed } \\
\text { Econ dell'Azienda } \\
\text { Maisano, Domenico; Politecnico di Torino, Dip.to Sistemi di Prod ed } \\
\text { Econ dell'Azienda } \\
\text { Mastrogiacomo, Luca; Politecnico di torino, Dip.to Sistemi di Prod } \\
\text { ed Econ dell'Azienda }\end{array}$ \\
\hline Keywords: & NETWORKS, DISTRIBUTED MANUFACTURING CONTROL, SENSORS \\
\hline Keywords (user): & wireless sensor networks, localization algorithms \\
\hline &
\end{tabular}

\section{(5) ScholaroNE" \\ Manuscript Central}




\title{
A Review of Localization Algorithms for Distributed Wireless Sensor Networks in Manufacturing
}

\author{
Fiorenzo Franceschini, Maurizio Galetto, Domenico Maisano, Luca Mastrogiacomo \\ POLITECNICO di TORINO \\ Dipartimento di Sistemi di Produzione ed Economia dell'Azienda \\ Corso Duca degli Abruzzi 24, 10129 - Torino, ITALY, \\ Tel. +39011 5647225, Fax. +39011 5647299, e-mail: fiorenzo.franceschini@ polito.it
}

\begin{abstract}
Wireless Sensor Networks (WSN) typically consist of a large number of densely populated sensor nodes. Due to important advances in integrated circuits and radio technologies, the use of distributed sensor networks is more and more widespread for a variety of applications, such as indoor navigation, environmental monitoring, people and objects tracking, logistics, industrial diagnostics, quality control, and other activities in manufacturing. In many cases, such as in objects tracking, knowing the physical location of network nodes is essential. Locating elements of WSNs is not a trivial task. Manual methods are wearisome and may be inaccurate, especially for large-scale networks. Therefore, many self-locating methods where nodes cooperate with each other without human involvement - have recently been studied and implemented.

The purpose of this work is to analyse the most significant methods for automatic locating of distributed WSNs. The first part of the paper provides a description of the most common criteria to categorize existing network localization algorithms. Then, we suggest a taxonomy which may be an useful tool to help evaluating, comparing, and selecting them. Five of the most representative algorithms are deeply explained and discussed, in order to identify their strong points, and their limitations.
\end{abstract}

Key words: distributed wireless sensor networks, localization algorithms, wireless networks, algorithm taxonomy, manufacturing.

\section{Introduction}

A wireless network typically consists of a large number of nodes (e.g. sensor devices) with a dense distribution, equipped with transceivers. Each device can communicate with other devices within its communication range. A wireless network is typically modelled as a graph, where each node represents a physical device. Two nodes are connected by an edge, if and only if, they can directly communicate. 
Dramatic advances in integrated circuits and radio technologies have made possible the use of large WSNs for many applications. In particular, the attention towards the utilization of WSNs in manufacturing is growing more and more. Since sensor devices do not need cables and may be easily deployed or moved, they can be practically utilized for a variety of industrial applications. Factory logistics and warehousing, environmental control and monitoring, support for assembly processes, industrial dimensional measuring, real-time surveillance, are only a part of possible applications of WSNs [Pepperl+Fuchs - 2005; Pan et al. - 2006; Koumpis et al. - 2005; Doss, Chandra - 2005; Franceschini et al. - 2006; Intel Corporation - 2005]. While outdoor localization applications are widespread today (see for example the Global Positioning System - GPS), also indoor applications can benefit from knowledge of location [Gotsman, Koren - 2004].

To make these applications feasible, device costs should be low, and the network should be organized without significant human involvement.

The solution of adding a GPS device to all the nodes in a network is not practical, for many reasons. GPS devices cannot work indoors, they are bulky, high-priced, and are inefficient in power consumption, while wireless sensor nodes are required to be small, low-priced, and low-powered [Bulusu, Heidemann, Estrin - 2000].

In some applications (e.g. indoor navigation, objects tracking, remote diagnostics etc.) mobile nodes calculate their position, making reference to fixed network nodes. So, fixed network nodes should be aware of their respective location. To reach this state - especially for largescale sensor networks - many self-localization methods have been recently studied and implemented. Generally, nodes automatically cooperate, estimating local distances to their neighbours, converging to a consistent coordinate assignment. Nodes work together in a peerto-peer way to build a map of the sensor network.

Received-Signal-Strength (RSS) and Time-of-Arrival (ToA) are two common approaches for estimating the distance between nodes within their mutual transmission range $[\mathrm{H}$. Wu, $\mathrm{C}$. Wang and N. Tzeng - 2005]. RSS measures the power of the signal at the receiver and calculates the distance according to the propagation loss model (see Error! Reference source not found.). ToA measures the propagation time $(\Delta \mathrm{t})$ of the received signal (typically radio signal for large distances or ultrasound for small distances) and determines the distance by multiplying it with its own speed. In general, RSS is easier to implement, while ToA may achieve higher accuracy [Patwari, Ash, Kyperountas, Hero III, Moses, Correal - 2005].

Take in Fig. 1 
In our technical laboratory at DISPEA - Politecnico di Torino (Italy) - we are developing a metrological application based on a WSN. Such an application requires a reasonable level of accuracy in distance estimates. As a consequence, inter-node distances are measured implementing a ToA technique, with ultrasound transceivers. Considering a speed of sound of around $340 \mathrm{~m} / \mathrm{s}$ (when temperature and relative humidity of the air are respectively $\mathrm{T}=20^{\circ} \mathrm{C}$ and $\mathrm{H} \approx 50 \%$ ), a propagation time $\Delta \mathrm{t}=10 \mathrm{~ms}$ corresponds to a distance $\mathrm{D}=\mathrm{v} \cdot \Delta \mathrm{t} \approx 3,4 \mathrm{~mm}$ between ultrasound transceivers. Let notice that - in the same propagation time $(\Delta t)-$ a radio signal (speed around $300000 \mathrm{~km} / \mathrm{s}$ ) cover a distance of $3000 \mathrm{~km}$ ! Limited resolution of timers is the main reason why ultrasound signals are preferable to radio signals for small distance measurements.

Angle of Arrival (AoA) is another approach for WSNs localization. Usually, sensor nodes receive the signals from at least three neighbours - in particular, collecting the angle information - and determine their coordinates by triangulation according to the angle bearings of incoming signals [Nasipuri, Li - 2002; Niculescu, Nath - 2003]. One potential problem of this approach is the expense of equipment to obtain precise angle estimates [Priyantha, Balakrishnan, Demaine, Teller - 2003].

Due to the greater drawbacks of implementing AoA techniques, in the following discussion we assume RSS or ToA approaches to estimate distances between neighbouring nodes.

\subsection{Applications of WSNs in Manufacturing}

To give a concrete idea of the potential of WSNs in manufacturing, this section briefly introduces some of the most interesting research issues.

1 - Support for final assembly. Ultrasonic sensors are mounted on power tools - for example screwdrivers - to detect their real position and activate them if they are in the right position, during final assembly [Pepperl+Fuchs - 2005].

2 - Industrial control and monitoring. Sensor devices can be deployed to perform industrial control and monitoring (for instance control of the air conditions of pollution, temperature, and pressure in different areas of the factory) or for emergency responses in case of incidents [Pan et al. - 2006; Koumpis et al. - 2005; Doss, Chandra - 2005].

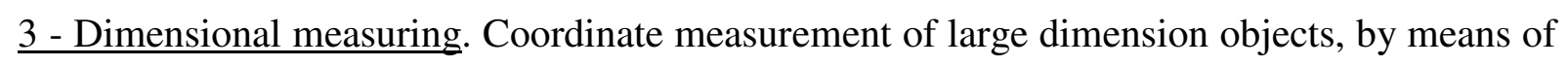
a wireless sensors "constellation" distributed around them. This research project is actually developed at the industrial metrology and quality laboratory of DISPEA - Politecnico di Torino [Franceschini et al. - 2006]. 
4 - Factory logistics and warehousing. A warehouse is an area of the industrial plant in which goods or merchandise are stored. Mobile forklifts generally move along corridors, in order to reach the shelves where goods are stored (see Error! Reference source not found.). Forklifts and shelves can be equipped with ultrasound transceivers communicating each other, with the purpose of evaluating mutual distances using a ToA technique [Intel Corporation - 2005]. This type of WSN can be utilized to calculate the position of the forklifts, in order to:

- Indoor Navigation. Mobile forklifts, equipped with wireless transceiver, are automatically guided towards their destination.

- Traffic Monitoring. The physical traffic can be monitored in order to identify the most congested areas or to improve goods distribution [Capkun, Hamdi, Hubaux - 2001].

\section{Take in Fig. 2}

\section{Scope and method of the review}

The purpose of this paper is to provide a reference framework of the major algorithms for automatic localization of network nodes. We suggest a taxonomy to evaluate and compare them. The first part of the paper provides a description of the most common criteria to categorize network localization algorithms. Subsequently, five of the most representative algorithms are independently described and set in the suggested taxonomy, in order to identify their common features, as well as those that set them apart. Considering the great abundance of algorithms presented in literature, they have been selected owing to their originality and spread. Finally, other network localization algorithms are briefly described. All algorithms are accompanied by explanatory representation schemes.

\subsection{Categorization of Network Localization Algorithms}

Generally, localization algorithms are designed to be applied to a typical sensor network, consisting of a large number of nodes with a dense distribution. As a consequence, many of them do not fit to small networks, with few distributed nodes. In this latter case, nodes can be manually located.

Localization algorithms can be classified within four categories:

1 - The first categorization is based on the presence (or absence) of nodes with pre-configured coordinates.

Anchor-based algorithms. The location system is implemented by selecting a set of reference nodes ("landmarks", "anchor-nodes") with known coordinates. A localization system, with 
"anchor-nodes", has the limitation that it needs another location system (e.g. GPS) to determine the anchor-nodes positions. Furthermore, a large number of anchor-nodes are required, for the resulting position errors to be acceptable [Priyantha, Balakrishnan, Demaine, Teller - 2003].

Anchor-free algorithms. They use local distance measurements among nodes to determine their respective coordinates. They do not assume the availability of nodes with pre-configured coordinates.

2 - The second categorization is based on the way node locations "propagate" in the network. Incremental algorithms. These algorithms usually start with a set of three or more reference nodes with known coordinates. Other nodes in the network can contact the reference nodes and determine their own coordinates. As an unknown position node obtains a acceptable position estimate, it may serve as a new reference point. This process can be incrementally applied until all nodes in the network have obtained their coordinates.

Concurrent algorithms. In this approach, many pairs of sensors communicate and share measurements, in order to achieve localization for all sensors. Rather than solving each sensor position one at time, all sensor positions are simultaneously estimated. Such localization systems not only allow unknown-location devices to make measurements with knownlocation references, but they additionally allow unknown-location devices to make measurements with other unknown-location devices. The additional information gained from these measurements between pairs of unknown-location devices enhances the accuracy and robustness of the localization system. Such systems have been described as "cooperative" [Patwari, Ash, Kyperountas, Hero III, Moses, Correal - 2005].

3 - The third categorization subdivides localization approaches into two broad classes, based on the "granularity" of information acquired by the sensors during communication.

Fine-grained algorithms. Algorithms that use accurate information - such as the distance from a reference point based on RSS or ToA measurements - fall into the category of fine-grained localization methods. Typically, they use technologies, such as infrared, ultrasound (US), or radio frequency $(\mathrm{RF})$ signals.

Coarse-grained algorithms. Algorithms that utilize less accurate information, such as proximity $^{1}$ to a given reference point, are categorized as coarse-grained localization methods.

\footnotetext{
${ }^{1}$ Two devices are considered to be "in proximity" if they can directly communicate.
} 
Coarse-grained algorithms estimate inter-node distances using rough techniques as hop-count. In a wireless network, the number of hops is the number of edges traversed by a signal, along the shortest path between the source node and the destination node. For example, in Error! Reference source not found. the number of hops between nodes $\mathrm{j}$ and $\mathrm{n}$ is 2 . Hop-count may be used to determine a rough evaluation of inter-node distances [Priyantha, Balakrishnan, Demaine, Teller - 2003].

As expected, fine-grained algorithms are more accurate than coarse-grained. In absence of measurement errors, fine-grained algorithms provide an exact network nodes positioning.

\section{Take in Fig. 3}

4 - The fourth categorization is based on computational distribution.

Centralized algorithms. Computing is performed by a single centralized node or network device. All nodes broadcast information to a single computer to solve the localization problem.

Distributed algorithms. Computing is equally distributed among network nodes. Each node receives location information from neighbouring nodes, performs computation, and retransmits the obtained results to them.

It is important to note that many of the algorithms discussed in the following sections have never been physically implemented on real sensor networks. Rather, most of them have been studied and developed on the basis of computer simulations. Few algorithms have been practically tested in WSNs. The complexity of such experimentation campaigns is due to the following main aspects: sensor firmware programming, sensor physical allocation, time taken to adjust the network and time for experiments [Patwari, Ash, Kyperountas, Hero III, Moses, Correal - 2005]. Regarding the future, additional effort is needed to test algorithms, in order to practically assess their performance and reliability.

\subsection{Taxonomy Description}

In this section we propose a taxonomy to benchmark network localization algorithms. Taxonomy is a useful tool for evaluating and comparing algorithms, depending on the network features and peculiarities. In the next section, five of the most representative localization techniques are illustrated and classified in detail.

Evaluation criteria are defined and described in Error! Reference source not found..

Take in Tab. 1 


\section{Detailed Description of Localization Algorithms}

In this section five of the most significant fine-grained localization algorithms are described in detail, following the criteria on the taxonomy presented before.

Finally, the descriptions of the algorithms are summarized in a table which may assist a network designer in evaluating and comparing them.

\subsection{Assumption Based Coordinates (ABC) algorithm}

The $\mathrm{ABC}$ algorithm is a $2 \mathrm{D} / 3 \mathrm{D}$, incremental and anchor-free algorithm [Savarese, Rabaey, Beutel - 2001]. It starts with a node $\left(\mathrm{n}_{0}\right)$ assuming that it is located at the origin of a local coordinate system. The algorithm localizes three (two in 2D networks) other nodes ${ }^{2}$ directly connected with $\mathrm{n}_{0}$, assigning them coordinates in order to satisfy the inter-node distances. To build such a local coordinate system the following assumptions are considered:

- $\mathrm{n}_{1}$ is located along the $\mathrm{x}$-axis;

- the direction of the positive $y$-axis is defined by $\mathrm{n}_{2}$;

- the direction of the positive $\mathrm{z}$-axis is defined by $\mathrm{n}_{3}$ (see Error! Reference source not found.).

\section{Take in Fig. 4}

The algorithm proceeds incrementally. Given a new node with unknown position it calculates its coordinates using the distances to four (or more) neighbours with already known coordinates.

In general, the trilateration problem can be formulated as follows. Given a set of nodes $\mathrm{n}_{\mathrm{i}}$ with known coordinates $\left(\mathrm{x}_{\mathrm{i}}, \mathrm{y}_{\mathrm{i}}, \mathrm{z}_{\mathrm{i}}\right)$ and a set of measured distances $\mathrm{D}_{\mathrm{i}}$, a system of equations needs to be solved to calculate the unknown position of $\mathrm{P}(\mathrm{u}, \mathrm{v}, \mathrm{w})$ [Chen, Cheng, Gudavalli 2003].

$$
\left[\begin{array}{c}
\left(\mathrm{x}_{1}-\mathrm{u}\right)^{2}+\left(\mathrm{y}_{1}-\mathrm{v}\right)^{2}+\left(\mathrm{z}_{1}-\mathrm{w}\right)^{2} \\
\left(\mathrm{x}_{2}-\mathrm{u}\right)^{2}+\left(\mathrm{y}_{2}-\mathrm{v}\right)^{2}+\left(\mathrm{z}_{2}-\mathrm{w}\right)^{2} \\
\vdots \\
\left(\mathrm{x}_{\mathrm{n}}-\mathrm{u}\right)^{2}+\left(\mathrm{y}_{\mathrm{n}}-\mathrm{v}\right)^{2}+\left(\mathrm{z}_{\mathrm{n}}-\mathrm{w}\right)^{2}
\end{array}\right]=\left[\begin{array}{c}
\mathrm{D}_{1}^{2} \\
\mathrm{D}_{2}^{2} \\
\vdots \\
\mathrm{D}_{\mathrm{n}}^{2}
\end{array}\right]
$$

If the trilateration problem is over defined (more equations than required to solve the localization problem), it can be solved using a least-mean squares approach [Savvides, Han, Strivastava - 2001].

\footnotetext{
${ }^{2}$ These nodes $\left(\mathrm{n}_{1}, \mathrm{n}_{2}, \mathrm{n}_{3}\right)$ are the first to establish a connection with $\mathrm{n}_{0}$.
} 
The accuracy depends heavily on the geometry of the position references, and the accuracy of distance measurements. Errors can propagate through all subsequent trilateration computations, leading to an inaccurate localization of nodes far away from $\mathrm{n}_{0}$.

\section{Network Features}

$\mathrm{ABC}$ is an anchor-free algorithm developed both for 2D and 3D network topologies. For widespread networks it can be inaccurate due to error propagation. To be located, in a 3D case each node has to communicate with at least four non-coplanar nodes with already known coordinates (three non-aligned in the 2D case, as shown in Error! Reference source not found.).

\section{Take in Fig. 5}

\section{Computational Workload}

The position estimation does not require centralized computation. All nodes are not required to communicate their connectivity information to a centralized computer in order to solve the localization problem. Computing is distributed among nodes with each:

- receiving ranging and location information from neighbouring nodes;

- solving a local localization problem;

- transmitting the results to neighbouring nodes.

The computational complexity for each node linearly increases with the number of localized neighbours. Each node performs $\mathrm{O}(\mathrm{n})$ computations, $\mathrm{n}$ being the number of neighbours already located.

\section{Benefits}

The algorithm is relatively simple and does not require complicate calculations. Furthermore, no anchor-nodes are required.

\section{Drawbacks}

$\mathrm{ABC}$ suffers from error propagation, the results being unsuitable for widespread networks. As with all incremental algorithms, error propagation is cumulative which results in poor coordinate assignment. In particular, positioning accuracy decreases for nodes that are distant from the "origin" node. Because of its incremental nature, the complete graph realization is not guaranteed even if every node of the network has four neighbours [Priyantha - 2003].

If measurements are corrupted by noise, however small, the algorithm can lead to ambiguous or incorrect nodes displacements. Error! Reference source not found. shows an example of a possible ambiguity. 
As all anchor-free algorithms, ABC will produce a topologically correct map with a random orientation relative to a global coordinate system. In fact, there are an infinite number of network solutions, since the coordinates can be rotated or translated as long as their distances do not change [Gotsman, Koren - 2004].

\section{Possible improvements}

A partial solution to error propagation consists in introducing a number of anchor-nodes. Since a global coordinate system is implicitly defined assigning anchor-nodes positions, the problem of network orientation is solved. In addition, the risk of incorrect nodes displacements is reduced. The price to pay for the introduction of anchor-nodes is the a priori manual location of them.

\subsection{Triangulation via Extended Range and Redundant Association of Intermediate Nodes (TERRAIN) algorithm}

TERRAIN algorithm builds on ABC algorithm, but it is anchor-based [Savarese, Rabaey, Beutel - 2001].

Nodes are divided into two categories:

- Anchor-nodes. Reference nodes with known coordinates. To start the algorithm, there must be at least four.

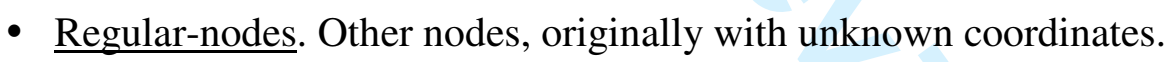

At first, each anchor-node starts executing an independent ABC algorithm (see Error! Reference source not found.). As a consequence, the number of different $\mathrm{ABC}$ algorithms, which will propagate within the network, corresponds to the number of anchor-nodes. Furthermore, each ABC assumes that the starting anchor-node is located at the origin of a local coordinate system. As explained in the section 3.1, such coordinate system is defined by selecting and localizing the next three regular-nodes. Then the algorithm incrementally proceeds. Regular-nodes calculate their coordinates, according to the locally defined system, using the distances to four (or more) already located neighbours.

In order to estimate distances from them, each regular-node waits until at least four independent $\mathrm{ABC}$ algorithms "propagate" to it from four anchor-nodes. At that time a standard trilateration can be performed. In general TERRAIN is more accurate than ABC [Savarese, Rabaey, Beutel - 2001]. As the number of anchor-nodes increases, the accuracy of position estimates improves.

Take in Fig. 6 
A similar approach is presented by Niculescu and Nath, who propose an Ad hoc Positioning System (APS) where at least three landmarks (with GPS receivers) are assumed to be available [Niculescu, Nath - 2001]. Nodes estimate the distance to these landmarks (that may be multiple hops away) according to the number of hop or the route distance obtained by a distance vector algorithm. Node coordinates can be calculated using the trilateration approach.

\section{Network Features}

As with the $\mathrm{ABC}$ algorithm, the TERRAIN algorithm is developed both for $2 \mathrm{D}$ and $3 \mathrm{D}$ networks. To be located, each node has to be reached by at least four different $\mathrm{ABC}$ algorithms, which start from as many anchor-nodes. The availability of four neighbours is a necessity but still may not be sufficient for a node location.

\section{Computational Workload}

The developed algorithm does not require centralized computation. Each single regular node plays the same role:

- receives ranging and location information from neighbouring nodes;

- solves a local optimization problem;

- transmits the obtained results to the neighbouring nodes.

The Computational Complexity for each node is evidently higher than ABC. The number of computations performed by each node is estimated to be $\mathrm{O}(\mathrm{m} \cdot(\mathrm{n}+1))$, where $\mathrm{n}$ is the number of neighbours and $\mathrm{m}$ the number of the $\mathrm{ABC}$ algorithms which has reached the node [Kahaner, Moler, Nash - 1988].

\section{Benefits}

This method reduces the error propagation, by the use of anchor-nodes and a final refinement process. Compared to ABC, TERRAIN is more accurate [Savarese, Rabaey, Beutel - 2001].

\section{Drawbacks}

If measurements are corrupted by noise the algorithm can lead to dramatically incorrect nodes displacements. The method is not able to prevent such ambiguities. Because of its incremental nature, the complete graph realization is not guaranteed.

\section{Possible improvements}

A first solution to prevent error propagation is to increase the number of anchor-nodes. A uniform distribution within the sensor network should guarantee low error accumulation. The price to pay is the a-priori localization of such nodes. A different kind of approach to improve location accuracy lead to the introduction of an iterative refinement process, where each node 
uses the range measurements and the most recently computed coordinates of each neighbour to refine its position. This process iterates several times until the locations of all the nodes converge. Average position errors are lower after this refinement and the iterative algorithm, starting from a reasonable graph realization, should reduce the risk of diverging [Savarese, Rabaey, Beutel - 2001].

\subsection{Savvides et al. Localization Algorithm}

This algorithm operates on an ad-hoc network where a small percentage of nodes know their own position (anchor-nodes) [Savvides, Han, Strivastava - 2001].

Before describing the algorithm, we introduce the concept of beacon and unknown node. Nodes with unknown positions are defined as unknown nodes, while localized nodes are called beacons. At the beginning only anchor-nodes are considered beacons.

Unknown nodes measure their distances from an adequate number of neighbouring beacons, and estimate their positions by performing a numeric optimization. The optimization, known as Maximum Likelihood, is obtained taking the Minimum Mean Square Estimate (MMSE) of an Error Function (EF), defined as the difference between the measured distances and the estimated Euclidean distances [Kahaner, Moler, Nash - 1988]:

$$
\mathrm{EF}=\frac{\sum_{\mathrm{i}=1}^{\mathrm{n}}\left[\mathrm{M}_{\mathrm{i}}-\mathrm{E}_{\mathrm{i}}\right]^{2}}{\mathrm{n}} \quad \text { being: }
$$

$\mathrm{M}_{\mathrm{i}}$ i-th inter-node measured distance (e.g. using RSS or ToA approaches);

$\mathrm{E}_{\mathrm{i}} \quad \mathrm{i}$-th inter-node Euclidean distance, obtained considering the nodes estimated positions;

$\mathrm{n}$ number of neighbouring beacons.

This process of estimation is defined as atomic multilateration.

Once an unknown node estimates its position, it becomes a beacon and broadcasts its position to other nearby unknown nodes, enabling them to estimate their locations. In general an unknown node will perform an atomic multilateration as soon as it receives information from at least four non-coplanar beacons (three non-aligned beacons in 2D networks). This process, defined as iterative multilateration, incrementally repeats until all the unknown nodes obtain an estimate of their position (see Error! Reference source not found.).

The algorithm is fully distributed, or alternatively, can be implemented by a single centralized node. In this latter case, the algorithm starts by estimating the position of the unknown node with the maximum number of beacons, using an atomic multilateration to obtain better accuracy and faster convergence. Similarly when an unknown node estimates its 
location, it becomes a beacon and this process repeats until the positions of all the nodes (which eventually have four or more neighbouring beacons) are estimated.

\section{Take in Fig. 7}

\section{Network Features}

This anchor-based algorithm is developed both for 2D and 3D networks. In 3D networks, each node must be connected with at least four non-coplanar beacons. In $2 \mathrm{D}$, it must be connected with at least three non-linear beacons. The presence of four neighbours is then a necessary but not a sufficient condition for a new node localization.

\section{Computational Workload}

The algorithm can work both in a distributed or centralized manner. In both ways, each node needs an atomic multilateration algorithm to be implemented.

Computational complexity for each node is estimated to linearly increase with the number of neighbouring beacons. Each node performs $\mathrm{O}(\mathrm{n})$ computations, $\mathrm{n}$ being the number of neighbours.

\section{Benefits}

The algorithm is relatively easy to be implemented, and it can be fully distributed.

\section{Drawbacks}

The algorithm suffers from error accumulation, providing inaccurate positions for nodes far from anchor-nodes. In the centralized version the error propagation is reduced by first localizing the most connected unknown nodes. Because of its incremental nature, the complete graph realization is not guaranteed. If measurements are corrupted by noise, the algorithm can lead to dramatically incorrect nodes displacements.

\section{Possible improvements}

Error propagation can be minimized through an iterative refinement process - for example, a numerical optimization such as mass-spring relaxation (see AFL algorithm) - performed after the nodes location.

\subsection{Anchor-Free Localization (AFL) algorithm}

AFL is a localization algorithm proposed by Priyantha et al. [Priyantha, Balakrishnan, Demaine, Teller - 2003]. The algorithm is concurrent, anchor-free, 2D/3D, and proceeds in two phases.

The first phase goal is to produce a qualitative network nodes graph. Arcs are weighted by considering the number of hops. Authors propose a coarse-grained approach to estimate inter- 
node distances using hop-count and radio connectivity, without using accurate ranging information from other technologies (e.g. ultrasound). The first phase of AFL can be considered a typical example of coarse-grained algorithm.

For clarity we describe the algorithm for a $2 \mathrm{D}$ network. The $3 \mathrm{D}$ network case is a simple extension.

The algorithm first elects five reference nodes: the first four nodes $\left(n_{1}-n_{4}\right)$ are selected on the periphery of the graph and the pair $n_{1}-n_{2}$ is roughly perpendicular to the pair nodes $n_{3}-n_{4}$. The remaining node $\left(\mathrm{n}_{5}\right)$ is elected in the "middle" of the graph (see Error! Reference source not found.). These five nodes are elected in five steps using a hop-count technique based exclusively on radio connectivity.

- $\underline{\text { Step } 1}$. Select an arbitrary node $\mathrm{n}_{0}$ (see Error! Reference source not found.). Then, select the reference node $n_{1}$ to maximize $h_{0,1}$ (hop-count between nodes $n_{0}$ and $n_{1}$, that is the number of nodes along the shortest radio path between nodes $n_{0}$ and $n_{1}$ ).

- Step 2. Select reference node $\mathrm{n}_{2}$ to maximize $\mathrm{h}_{1,2}$ (hop-count between nodes $\mathrm{n}_{1}$ and $\mathrm{n}_{2}$ ).

- Step 3. Select reference node $\mathrm{n}_{3}$ to minimize $\mathrm{lh}_{1,3}-\mathrm{h}_{2,3} \mathrm{l}$ and maximize $\mathrm{h}_{1,3}+\mathrm{h}_{2,3}$. This step selects a node that is roughly equidistant from $\mathrm{n}_{1}$ and $\mathrm{n}_{2}\left(1^{\text {st }}\right.$ condition), and is "far away" from them $\left(2^{\text {nd }}\right.$ condition).

- $\underline{\text { Step 4. }}$. As in the previous step, select reference node $\mathrm{n}_{4}$ to minimize $\left|\mathrm{h}_{1,4}-\mathrm{h}_{2,4}\right|$ and minimize $h_{3,4}$. This optimization selects a node roughly equidistant from nodes $n_{1}$ and $n_{2}$, while being furthest from node $n_{3}$.

- Step 5. As in the previous step, select reference node $\mathrm{n}_{5}$ to minimize $\left|\mathrm{h}_{1,5}-\mathrm{h}_{2,5}\right|$ and maximize $\mid \mathrm{h}_{3,5}-\mathrm{h}_{4,5}$ l. This optimization selects the node representing the rough "center" of the graph.

\section{Take in Fig. 8}

This heuristic approach uses the hop-counts from the chosen reference nodes $\left(h_{1, i}, h_{2, i}, h_{3, i}\right.$, $\mathrm{h}_{4, \mathrm{i}}, \mathrm{h}_{5, \mathrm{i}}$ ) to determine approximate node coordinates. Further details about the heuristic method can be found in the original paper [Priyantha, Balakrishnan, Demaine, Teller - 2003].

The second phase of the AFL algorithm is fine-grained. Inter-node distances are determined using a more accurate measurements technique based on ToA. This is a concurrent phase. Nodes positions are estimated simultaneously by implementing a mass-spring optimization. Nodes are interpreted as concentrated masses, linked by springs. The force, that each spring applies to linked nodes, depends on the difference between inter-node estimated distances and actual distances (using the ToA method). The starting estimate of inter-node distances is 
provided by the first phase of AFL. Nodes are gradually moved in order to minimize spring forces providing a more plausible node configuration.

In more detail, each node $\left(\mathrm{n}_{\mathrm{i}}\right)$ periodically sends its estimated position $\left(\mathrm{p}_{\mathrm{i}}\right)$ to all its neighbours. Each node also knows the estimated position of all its neighbours. Using these positions node $n_{i}$ calculates the estimated distance $\left(d_{i, j}\right)$ to each neighbour $\left(n_{j}\right)$. It also knows the distance $\left(r_{i, j}\right)$, measured using ToA. Let $v_{i, j}$ represent the direction unit vector from $p_{i}$ (estimated position of $i$-th node) to $p_{j}$ (estimated position of $j$-th node). The force $F_{i, j}$ along the direction $v_{i, j}$ is given by: $F_{i, j}=v_{i, j}\left(d_{i, j}-r_{i, j}\right)$.

The resultant force on the node $n_{i}$ is given by: $\vec{F}_{i}=\sum_{j=1}^{N} \vec{F}_{i, j}, N$ being the number of neighbours.

The energy $E_{i, j}$ of nodes $n_{i}$ and $n_{j}$, due to the difference in the measured and estimated distances, is directly proportional to the square of $\left|F_{i, j}\right|$. The total energy of node $n_{i}$ is equal to: $E_{i}=\sum_{j=1}^{N} E_{i, j} \propto \sum_{j=1}^{N}\left(d_{i, j}-r_{i, j}\right)^{2}$

The total energy of the system $(\mathrm{E})$ is given by $\mathrm{E}=\sum_{\mathrm{i}=1}^{\mathrm{N}} \mathrm{E}_{\mathrm{i}}$.

In order to reduce its energy $\left(\mathrm{E}_{\mathrm{i}}\right)$, each node $\left(\mathrm{n}_{\mathrm{i}}\right)$ moves, one by one, by an infinitesimal amount in the direction of the resultant force $\left(\mathrm{F}_{\mathrm{i}}\right)$. The location of the node is updated and the node broadcasts its new location to its neighbours (see Error! Reference source not found.). Whenever a node receives a location update from its neighbours, it recalculates its total force and updates its location.

The mass-spring optimization terminates when the resultant forces $\left(F_{i}\right)$ of nodes decrease to zero.

\section{Take in Fig. 9}

A similar approach is presented by Howard et al.'s [Howard, Mataric, Sukhatme - 2001]. In their system, robots equipped with odometric equipment (instrument indicating the distance travelled) move through an environment, assigning approximate initial positions to beacons. Then, beacons run a distributed spring-based relaxation procedure.

Gotsman and Koren algorithm is analogous to AFL. It works in two phases. First phase produces a qualitative network nodes graph, while second phase performs an optimization of the network layout [Gotsman, Koren - 2004].

$\mathrm{Wu}$ et al. propose a self-configurable positioning technique, quite similar to AFL, to built upon two models [Wu, Wang, and Tzeng - 2005]. First, for a given node distribution, the 
distance between two nodes (usually multiple hops away) is estimated according to the length of the shortest path. Second, a number of stable nodes are selected to serve as landmarks. Every landmark estimates its distance to other landmarks exchanging obtained distance information. Once a landmark has accumulated a full set of distances between any two landmarks in the network, it may start establishing the coordinates system by minimizing an error objective function. This latter is defined as the difference between the actual distance and the distance measured in the established coordinates system. Other nodes in the network calculate their coordinates by similarly minimizing the error distances from landmarks.

\section{Network Features}

AFL is an anchor-free algorithm which applies only to multi-hop networks. In small singlehop networks, where all nodes are connected each other, it fails. The first phase, based on the hop-count, can not be executed. AFL applies to both 2D and 3D networks.

\section{Computational Workload}

The first phase of AFL is far from being distributed. It can hardly be implemented without a centralized network device which handles information from nodes. The second phase of the algorithm is fully distributed, however, it can be quite slow, since multiple iterations are required [Gotsman, Koren - 2004]. AFL performances have been evaluated by computer simulations, so it is difficult to provide precise data on the computational workload. AFL is more time-consuming than pure incremental algorithms, due to the number of iterations required. During a single iteration of mass-spring optimization, each node performs $\mathrm{O}(n)$ computations, $n$ being the number of neighbours.

\section{Benefits}

AFL is anchor-free and does not require nodes with pre-configured coordinates. As opposed to incremental algorithms, AFL performs much better, even for networks with small connectivity [Priyantha, Balakrishnan, Demaine, Teller - 2003]. Furthermore, AFL error propagation is small.

\section{Drawbacks}

Authors do not guarantee the first phase always succeed. It may fail for two reasons:

1. location estimation is extremely rough, especially if the sensor network is composed of few nodes;

2. in single-hop networks, where all nodes are connected each other, hop-count estimation of inter-node distances does not work. 
In general, simulations and practical experiments have demonstrated that a pure mass-spring algorithm can produce networks with incorrect layouts, if initial position estimates are not good [Priyantha, Balakrishnan, Demaine, Teller - 2003]. The success of the first phase is fundamental for the whole success of the algorithm. Even if AFL outperforms incremental algorithms, there is not a proof of correctness. AFL may converge to distorted network node configurations. If measurements are corrupted by noise the algorithm can lead to dramatically incorrect nodes displacements.

\section{Possible improvements}

Present and future improvements are focused on enhancing the first phase. In the actual version, the algorithm lacks a method to prevent realization ambiguities and does not fit widespread networks, resulting hardly scalable because of the high communication costs. Research effort focuses on a possible way to realize a completely distributed first phase with such requirements [Gotsman, Koren - 2004].

\subsection{Moore et al. Localization Algorithm}

Moore et al. propose a robust distributed algorithm for localizing nodes in a WSN in which measurements are corrupted by noise [Moore, Leonard, Rus, Teller - 2004]. In particular, the authors consider how measurement noise can cause incorrect realization of node displacement (see Error! Reference source not found.).

The great benefit of the proposed algorithm is to prevent this ambiguity, increasing positioning accuracy compared to a pure incremental algorithm (e.g. Savvides et al. algorithm).

\section{Take in Fig. 10}

The algorithm is anchor-free, fine-grained, and it has been physically implemented in 2D sensor networks [Moore, Leonard, Rus, Teller - 2004]. Before describing the algorithm, we introduce the concept of cluster, and robust quadrilateral.

A cluster consists of a node and its single-hop neighbours. A robust quadrilaterals is an additional constraint which permits localization of only those nodes which have a high likelihood of unambiguous realization. According to Moore et al., localization based on robust quadrilaterals attempts to prevent incorrect realizations of ambiguities.

The algorithm proposed is based on three phases (see Error! Reference source not found.). In the first phase each node becomes the centre of a cluster and estimates the relative location of neighbours, which can be unambiguously identified. Therefore nodes with ambiguous 
locations are not used for further nodes localization. The basic idea of first phase is that missing localization information for a few probably ambiguous nodes is preferential to estimate incorrect information.

This incremental process, called "cluster localization" is based on trilateration, and "robust quadrilaterals".

\section{Take in Fig. 11}

The second phase is an optional cluster optimization. It refines the position estimates for each cluster using numerical optimization such as mass-spring relaxation with the full set of measured distance constraints (see AFL algorithm). This phase reduces and redistributes any accumulated error that results from the incremental approach used in the first phase. It can be omitted if maximum efficiency is desired.

The third phase computes transformations between the local coordinate systems of neighbouring clusters by finding the set of nodes in common between two clusters and solving for the rotation, translation, and possible reflection that best aligns the clusters. This phase is implemented using a "cluster stitching" technique, presented by Horn [Horn - 1987]. When the third phase is complete, any local cluster coordinate systems are reconciled into a unique global coordinate system.

\section{Take in Fig. 12}

Capkun et al. presented an analogous localization method working with clusters. Each node establishes a local coordinate system for a cluster, composed by itself and its one-hop neighbours. Clusters are then stitched together to obtain a coordinate assignment for all the nodes, within a general coordinates system [Capkun, Hamdi, Hubaux - 2001]. This technique, unlike that of Moore et al., does not consider how measurement noise can cause incorrect realization of network displacement, and does not prevents this sort of ambiguity [Moore, Leonard, Rus, Teller - 2004].

\section{Network Features}

The localization algorithm is anchor-free. It can be applied to single-hop and multi-hop networks. It is not easily scalable to large networks due to the need for centralized computation in cluster "stitching". Until now, it has been implemented only in 2D networks.

\section{Computational Workload}

The first phase of the algorithm is based on trilateration, preceded by non-ambiguity testing. The second phase is a mass-spring relaxation, analogous to the AFL, used to refine the 
localization of clusters. As a consequence, the algorithm can be quite slow, requiring multiple iterations. These optimizations are performed per cluster and not the network as a whole, thus allowing concurrent processing.

The third phase can hardly be implemented without a centralized network device handling information from clusters which should be stitched together. In this phase, clusters are stitched using a closed form solution for a least-squares problem. Such a problem is relatively complex, with computations required to solve systems of polynomial equations [Horn - 1987]. The third phase has been exclusively evaluated by computer simulation.

As expected, the computational complexity for each cluster grows with respect to the number of neighbours. For each node, the computation depends on the third power $\mathrm{O}\left(\mathrm{n}^{3}\right)$ of the number of neighbours (n) [Moore, Leonard, Rus, Teller - 2004].

\section{Benefits}

The algorithm significantly reduces the amount of error propagation over approaches based on basic trilateration. Simulations show that error on node positioning using incremental methods is more than double those using the Moore et al. method [Moore, Leonard, Rus, Teller - 2004].

\section{Drawbacks}

The drawback of Moore's approach is that under conditions of low node connectivity or high measurement noise, the algorithm may be unable to localize a useful number of nodes [Moore, Leonard, Rus, Teller - 2004]. However, for many applications, missing localization information for a known set of nodes is preferential to incorrect information for an unknown set. In 3D networks, computational complexity and data routing dramatically increase.

\section{Possible improvements}

When robust quadriterals do not exists or when the connectivity is poor, Moore et al. algorithm fails. To get over these difficulties, the algorithm can be enhanced implementing a more effective robustness test, such as the one proposed by Sottile and Spirito (2006).

\section{Summary of Localization Algorithms}

The previous section provided a detailed description of five more significant fine-grained localization algorithms. As early discussed, fine-grained algorithms are more accurate than coarse-grained. They utilize more accurate inter-node distances, usually obtained through RSS or ToA techniques. These algorithms are suitable for applications where nodes are required to be localized with a fair level of accuracy. In object tracking, for example, accurate 
localizations of network nodes lead to accurate locating of objects moving within the network. On the other hand, coarse-grained algorithms provide a rougher localization of nodes, but they are simpler to be implemented.

In this section, the five localization algorithms are compared according to the taxonomy presented in Error! Reference source not found.. Identified criteria can be useful to evaluate and compare different network localization techniques. The aim is to provide a reference scheme to select them, depending on network characteristics (see Error! Reference source not found.).

\section{Take in Tab. 2}

Considering the actual research issues related to localization algorithms, there is lot of room for improvements. Several researchers are trying to develop the existing algorithms in order to make them work in non optimal conditions (for example incomplete connectivity, presence of moving sensors) [Taylor et al. - 2005; Sottile, Spirito - 2006]. Additional effort is being spent to bridge the gap between simulations and real-world localization systems, gathering more data on the real behaviour of sensor nodes, particularly with respect to physical effects like multipath, interference, and obstruction [Langendoen and Reijers - 2003]. Furthermore, other research groups are studying the problem of "directional localization", where each network node not only must be aware its position but also its orientation relative to the network [Akcan et al. - 2006].

\section{Conclusions}

In many applications of WSNs, it is crucial to determine the physical location of nodes. Automatic localization of nodes in wireless networks is a key to enable most of these applications. As an example, we considered a sensor network deployment within a warehouse. Making sensors wireless and self-configurable reduces the high cost of cabling and makes the network more manageable and dynamic.

Numerous network localization algorithms have been recently proposed and developed by many authors. Similarities are present in each different approach [Langendoen, Reijers 2003; Patwari, Ash, Kyperountas, Hero III, Moses, Correal - 2005]. This paper suggests a new taxonomy to help evaluate, compare, and select network localization algorithms, depending on the network characteristics, and the type of applications.

The paper focused on five fine-grained techniques, due to their better accuracy and their better chances of being applied to many contexts (e.g. quality control, indoor navigation, 
logistics, warehousing, remote diagnostics etc.). Algorithms have been discussed in detail, in order to summarize their characteristics and peculiarities.

Many algorithms have never been tested in practice. Additional effort is needed to test algorithms with practical experiments, and not only through simulations, in order to assess their performance and reliability. Various algorithms are in testing on two specific applications at the industrial metrology and quality laboratory of DISPEA - Politecnico di Torino:

1. Innovative techniques for taking coordinate dimensional measurements of objects, using distributed wireless sensors [Franceschini, Galetto, Settineri - 2002].

2. Wireless monitoring of systems with changeable configuration (e.g. cranes, mechanical arms, automatic gates etc..) to check their "natural" positions.

Since these applications require a reasonable level of accuracy in inter-node distance estimates, network nodes are equipped with ultrasound transceivers implementing a ToA technique.

\section{References}

Akcan, H., Kriakov, V., Brönnimann, H., Delis A. (2006) GPSFree Node Localization in Mobile Wireless Sensor Networks. In Proceedings of MobiDE'06, Chicago, Illinois, USA.

Bulusu, N., Heidemann, J., Estrin, D. (2000) GPS-less low cost outdoor localization for very small devices. IEEE Pers. Commun. Mag., Vol. 7, No 5, pp. 28-34.

Capkun, S., Hamdi, M., Hubaux, J. P. (2001) GPS-free positioning in mobile ad-hoc networks. In Proceedings of the $34^{\text {th }}$ Hawaii International Conference on System Sciences.

Chen, M., Cheng, F., Gudavalli, R. (2003) Precision and Accuracy in an Indoor Localization System. Technical Report CS294-1/2, University of California, Berkeley, USA.

Doherty, L., Pister, K. S. J., and Ghaoui, L. E. (2001) Convex position estimation in wireless sensor networks. In Proc. IEEE INFOCOM, Anchorage, AK, pp. 1655-1663.

Doss, R.C., Chandra D. (2005) Reliable Event Transfer in Wireless Sensor Networks Deployed for Emergency Response. In Proceedings of the 17th IASTED International Conference on Parallel and Distributed Computing and Systems PDCS 2005, Phoenix, AZ, USA.

Franceschini, F., Galetto, M., Maisano, M., Mastrogiacomo, L. (2006) Mobile Spatial coordinate Measuring System (MScMS) - Introduction to the system. Work-in-progress, DISPEA - Politecnico di Torino, Italy.

Franceschini, F., Galetto, M., Settineri, L. (2002) On-Line Diagnostic Tools for CMM Performance. The International Journal of Advanced Manufacturing Technology, Vol. 19, No. 2, pp. 125-130.

Gotsman, C., and Koren, Y. (2004) Distributed Graph Layout for Sensor Networks. In Proceedings of Graph Drawing 12th International Symposium, New York, Vol. 3383/2005 pp. 273-284. 
Horn, B. K. P. (1987) Closed form solution of absolute orientation using unit quaternions. Journal of the Optical Society A 4, No. 4, pp 629-642.

Howard, A., Mataric, M., and Sukhatme, G. (2001) Relaxation on a mesh: A formalism for generalized localization. In Proceedings IEEE/RSJ Intl. Conf. on Intelligent Robots and Systems (IROS), Wailea, Hawaii.

Kahaner, D., Moler, C., Nash, S. (1988) Numerical methods and software. Prentice-Hall, EngleWood Cliffs, New Jersey.

Koumpis, K., Hanna, L., Andersson, M., Johansson, M. (2005) Wireless Industrial Control and Monitoring beyond Cable Replacement. In Proceedings PROFIBUS International Conference, Coombe Abbey, Warwickshire, UK.

Intel Corporation (2005) Expanding Usage Models for Wireless Sensor Networks. Technology@Intel Magazine, http://www.intel.com/technology/magazine/research/sensornetworks-0805.pdf.

Ji, X., and Zha, H. (2004) Sensor positioning in wireless ad-hoc sensor networks using multidimensional scaling. In Proceedings IEEE INFOCOM.

Langendoen, K., and Reijers, N. (2003) Distributed Localization in Wireless Sensor Networks: A Quantitative Comparison. Computer Networks, Vol. 43, No. 4, pp. 499-518.

Moore, D., Leonard, J., Rus, D., and Teller, S. S. (2004) Robust distributed network localization with noisy range measurements. In Proceedings of SenSys 2004, Baltimore, MD, pp. 50-61.

Nagpal, R., Shrobe, H., and Bachrach, J. (2003) Organizing a Global Coordinate System from Local Information on an Ad Hoc Sensor Network. In Proceedings International Workshop on Information Processing in Sensor Networks (IPSN 2003), Palo Alto, CA.

Nasipuri, A., Li, K. (2002) A directionality based location discovery scheme for wireless sensor networks. In Proceedings of ACM International Workshop on Wireless Sensor Networks and Applications (WSNA'02), pp. 105-111.

Niculescu, D., and Nath, B. (2001) Ad hoc positioning system (APS). In Proceedings of IEEE Global Communications Conference (GlobeCom'01), pp. 2926-2931.

Niculescu, D., and Nath, B. (2003) Ad hoc positioning system (APS) using AOA. In Proceedings of IEEE Annual Joint Conference IEEE Computer and Communications Societies (INFOCOM'03), pp. 1734-1743.

Oh, S., Chen, P., Manzo, M., Sastry S. (2006) Instrumenting Wireless Sensor Networks for Real-Time Surveillance in Proc. of the International. Conference on Robotics and Automation, Orlando, Florida.

Pan, M., Tsai, C., Tseng, Y. (2006) Emergency Guiding and Monitoring Applications in Indoor 3D Environments by Wireless Sensor Networks, Tech. Rep. http://www.cs.berkeley.edu/ kamin/pubs/icra06_mttvideo.pdf.

Patwari, N., Ash, J., Kyperountas, S., Hero III, A., Moses, R., Correal, N. (2005) Locating the Nodes - Cooperative localization in wireless sensor networks. IEEE Signal processing Magazine, Vol. 22, No. 4, pp. 54-69.

Pepperl+Fuchs (2005) Internal Report on Factory Automation. http://www.pepperl-fuchs.com.

Priyantha, N. B., Balakrishnan, H., Demaine, E., and Teller, S. (2003) Anchor-free distributed localization in sensor networks. Tech. Rep. 892, MIT Lab. for Comp. Sci. 
Savarese, C., Rabaey, J., and Beutel, J. (2001) Locationing in Distributed Ad-Hoc Wireless Sensor Networks. In Proceedings of ICASSP, Salt Lake City, UT, pp. 2037-2040.

Savarese, C., Rabaey., J. (2002) Robust positioning algorithms for distributed ad hoc wireless sensor networks. In Proceedings of USENIX Annual Technical Conference, Monteray, CA.

Savvides, A., Garber, W., Adlakha, S., Moses, R., Strivastava, M. B. (2003) On the error characteristics of multihop node localization in ad-hoc sensor networks. In Proceedings of IPSN, Palo Alto, CA, pp. 317-332.

Savvides, A., Han., C., and Strivastava, M. B. (2001) Dynamic fine-grained localization in ad hoc networks of sensors. In Proceedings of ACM/IEEE $7^{\text {th }}$ Annual International Conference on Mobile Computing and Networking (MobiCom'01), pp. 166-179.

Sottile, F., Spirito, M. (2006) Enhanced Quadrilateral-based Localization for Wireless Ad-hoc Networks. In Proceedings of IFIP Fifth Annual Mediterranean Ad Hoc Networking Workshop (Med-Hoc-Net 2006), June 14-17, Lipari, Italy.

Taylor, C., Rahimi, A., Bachrach, J. Shrobe, H. (2005) Simultaneous Localization, Calibration, and Tracking in an ad Hoc Sensor Network. Tech. Rep., Computer Science and Artificial Intelligence Laboratory of MIT, https://dspace.mit.edu/handle/1721.1/30541.

Wang, L. and Xi, F. (2006) Challenges in design and manufacturing. International Journal of Computer Integrated Manufacturing, Vol. 19, No. 5, pp. 409-410.

Ward, A., Jones, A., and Hopper, A. (1997) A new location technique for the active office. IEEE Personal Communications, Vol. 4, No. 5, pp. 42-47.

Wu, H., Wang, C., and Tzeng, N. (2005) Novel Self-Configurable Positioning Technique for Multihop Wireless Networks. IEEE/ACM Transactions on Networking, Vol. 3, No.3, pp. 609621. 


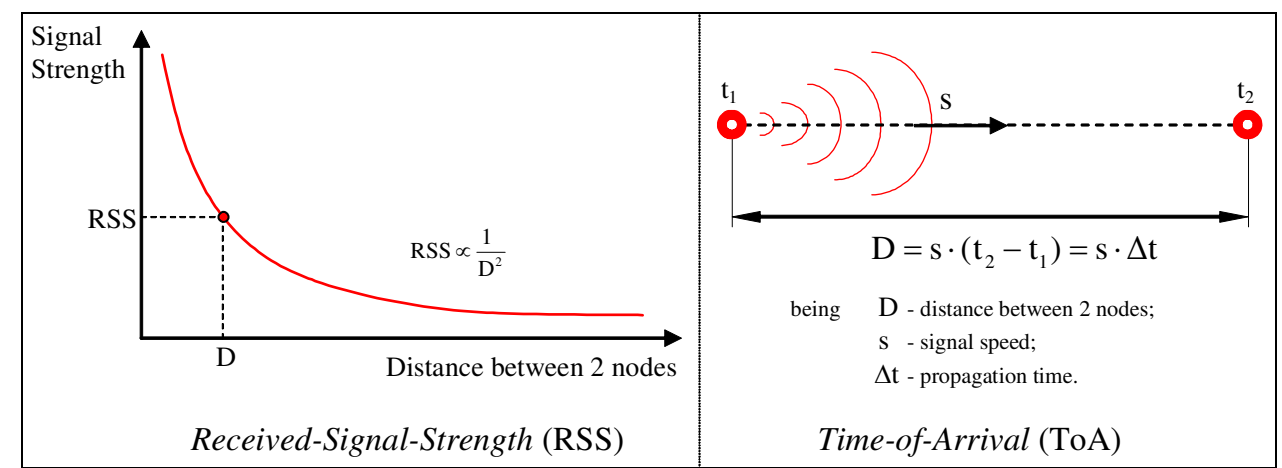

Fig. 1 - Representation scheme of RSS and ToA approaches for distance estimation

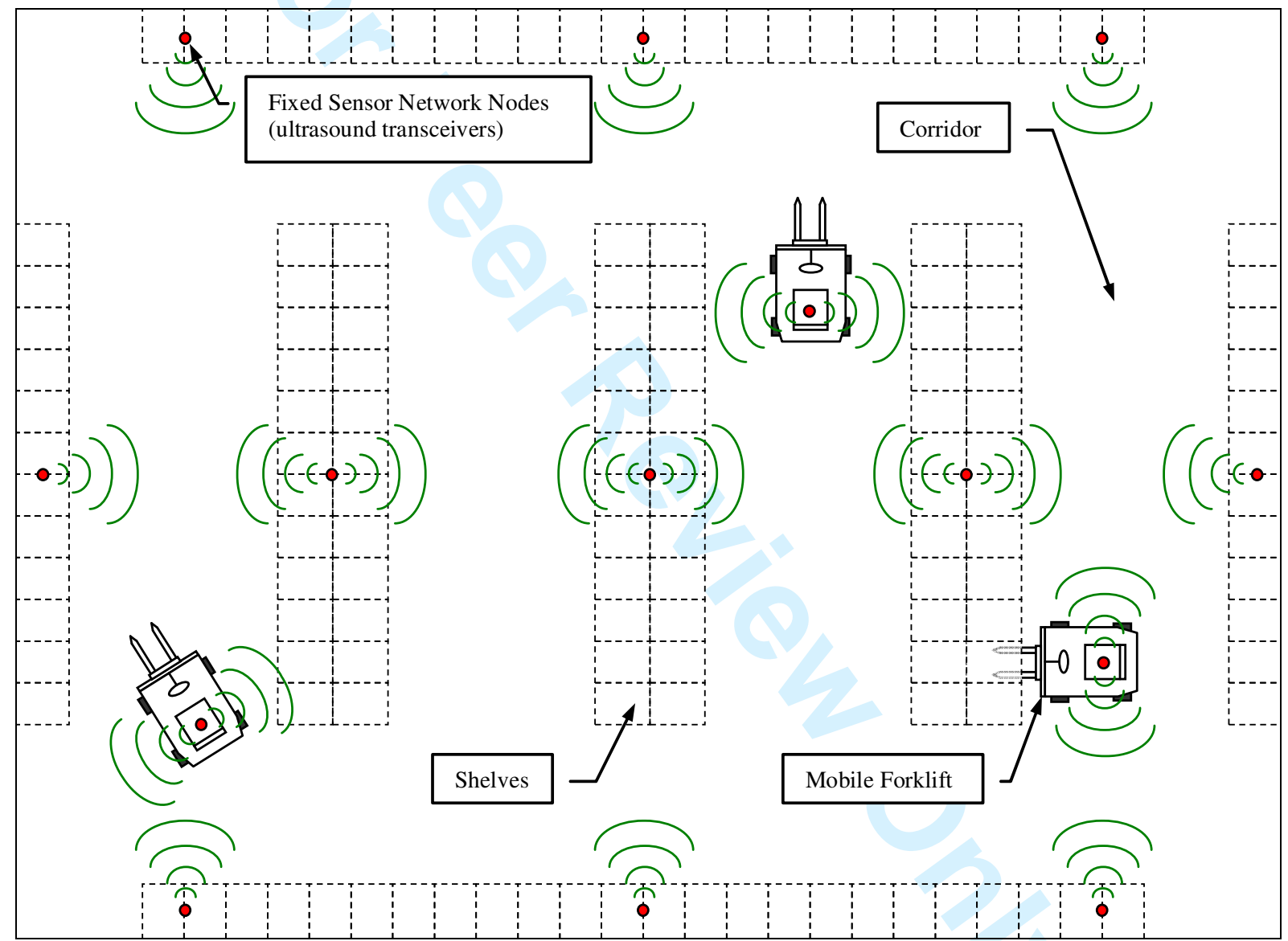

Fig. 2 - Schematic layout: industrial warehouse equipped with a network of wireless sensors.

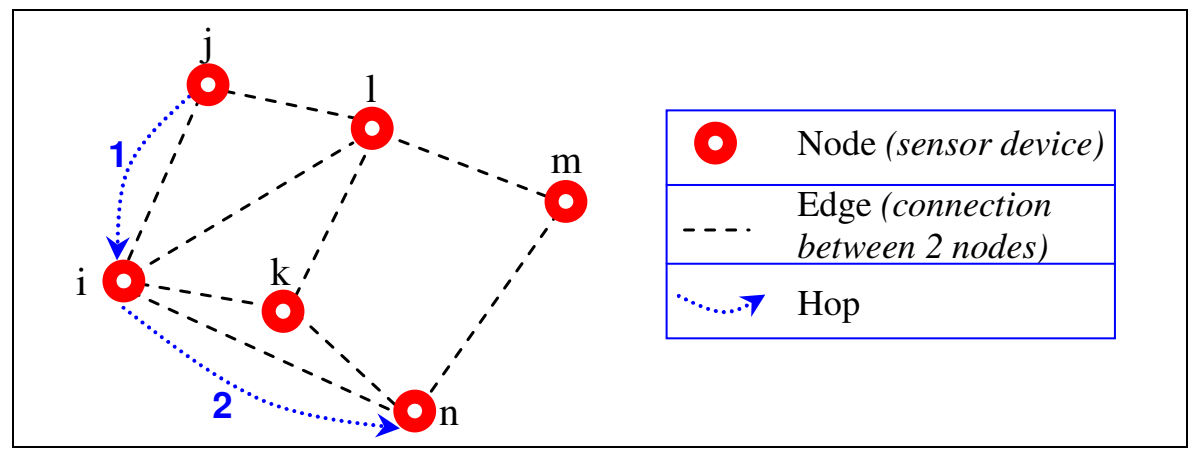

Fig. 3 - Schematic representation of the concept of hop count in a sensor network 


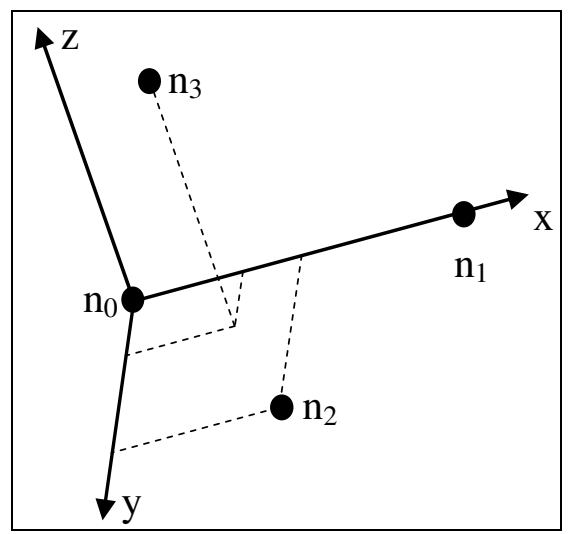

Fig. 4 - Local coordinate system built around the starting node $\left(\mathbf{n}_{0}\right)$

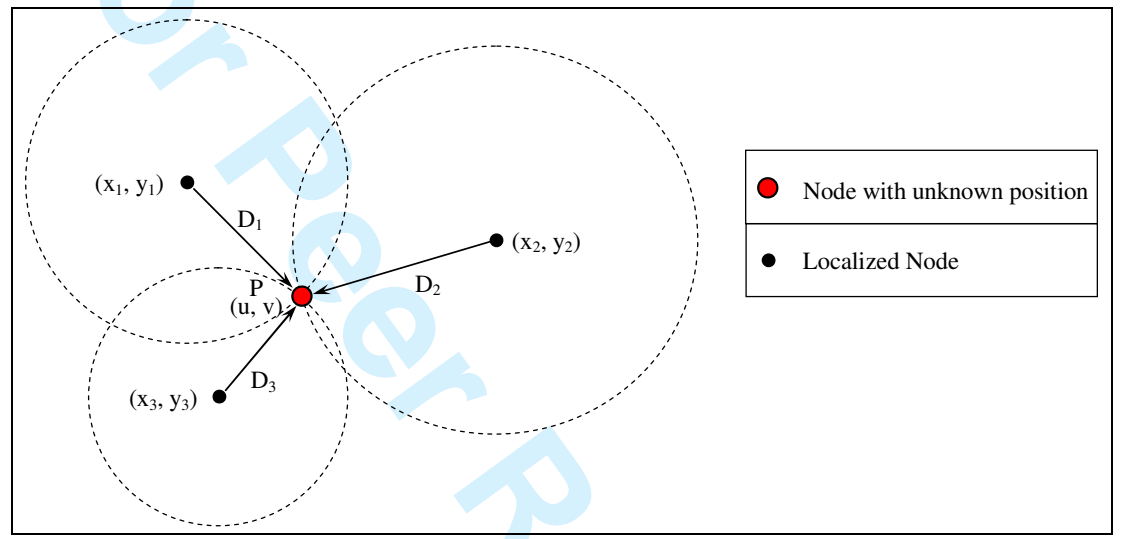

Fig. 5 - Representation scheme of the trilateration problem in a 2D network

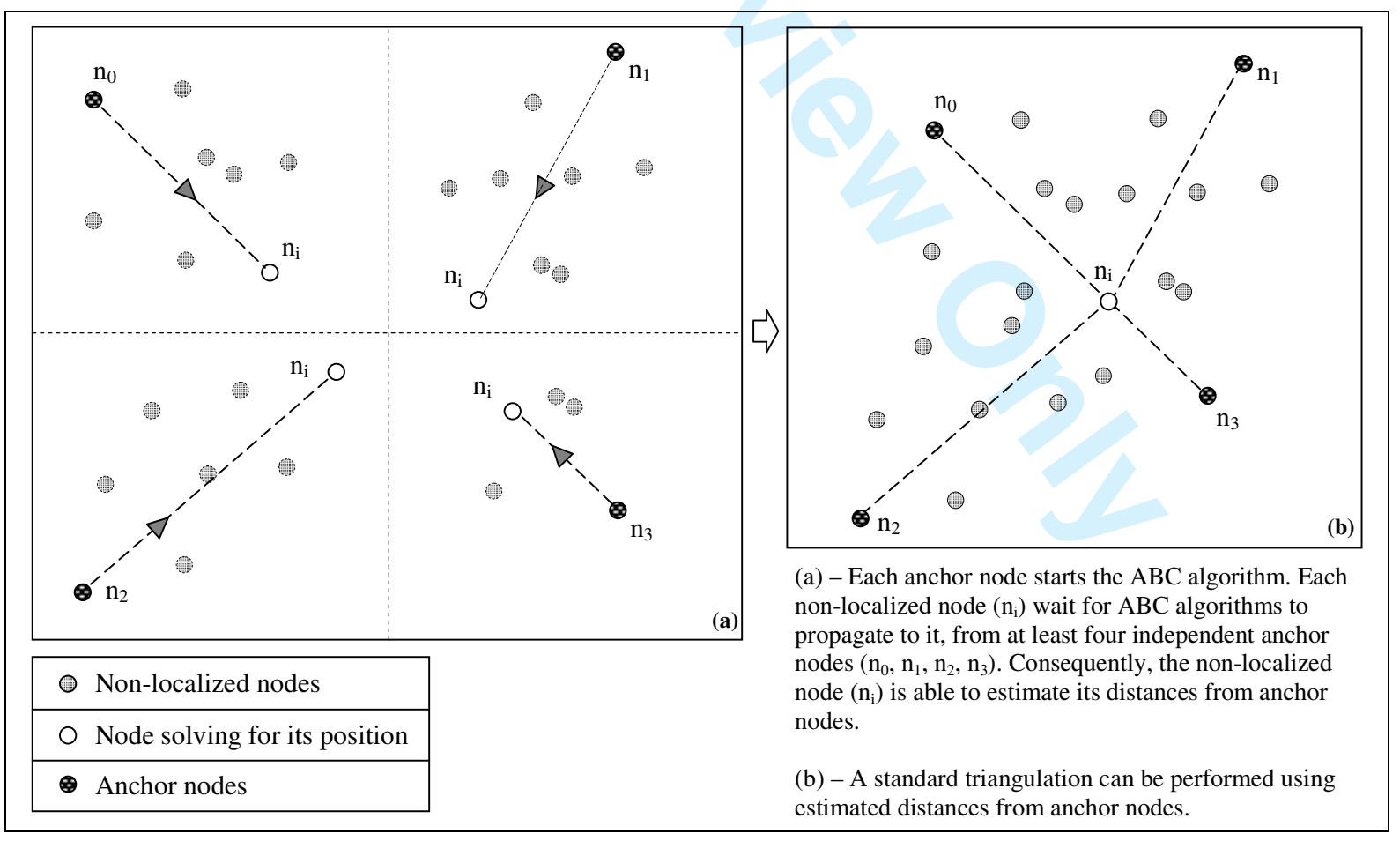

Fig. 6 - Schematic representation of TERRAIN algorithm 


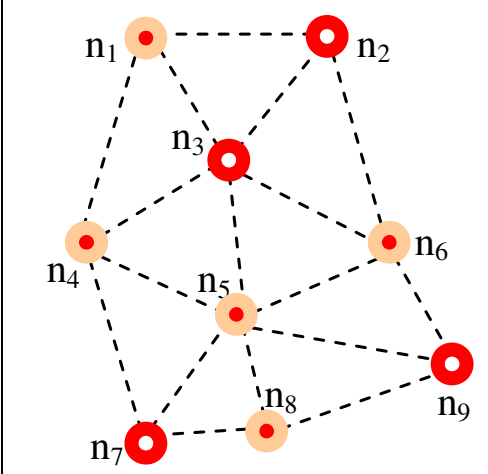

(a) at the beginning only anchor-nodes $\left(\mathrm{n}_{1}, \mathrm{n}_{4}, \mathrm{n}_{5}, \mathrm{n}_{6}, \mathrm{n}_{8}\right)$ know their positions (beacons).

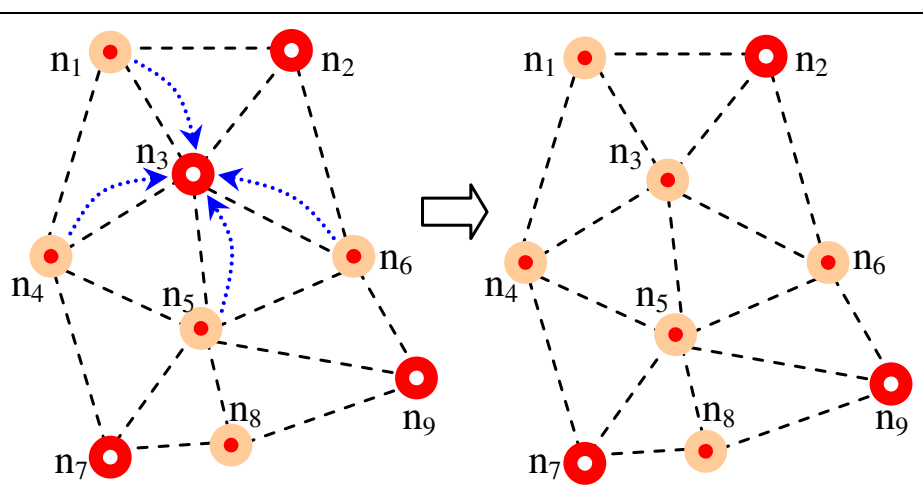

(b) Atomic Multilateration: an unknown node $\left(\mathrm{n}_{3}\right)$ measures its distances from neighbouring beacons $\left(\mathrm{n}_{1}, \mathrm{n}_{4}, \mathrm{n}_{5}, \mathrm{n}_{6}\right)$ and estimates its own position performing a Maximum Likelihood optimization.
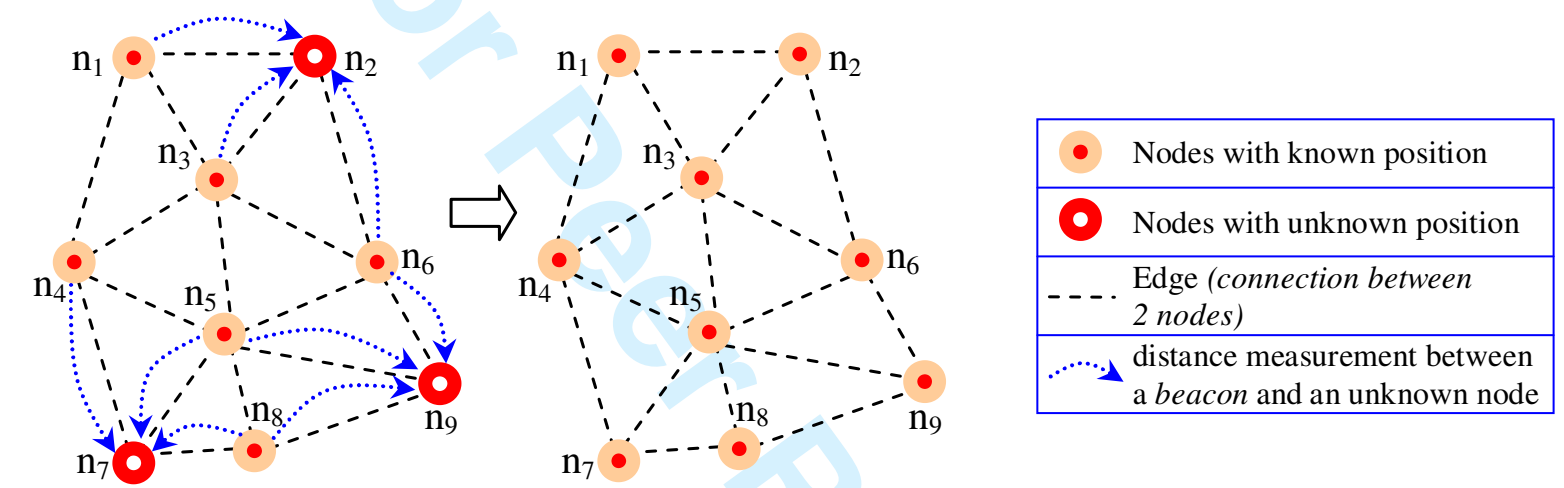

(c) Iterative Multilateration: once unknown node $\left(\mathrm{n}_{3}\right)$ estimates its

position, it becomes a beacon. The positioning process incrementally

repeats until all the unknown nodes obtain an estimate of their position.

Fig. 7 - Schematic representation of Savvides et al. Localization Algorithm [Savvides et al. - 2001]

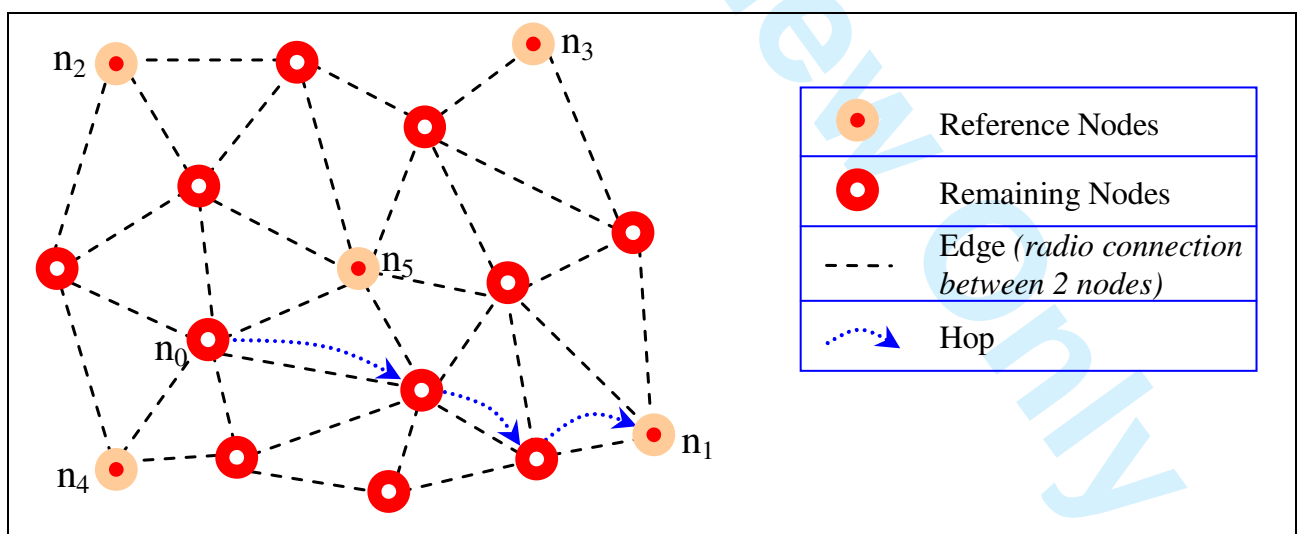

Fig. 8 - First phase of AFL: election of five reference nodes 


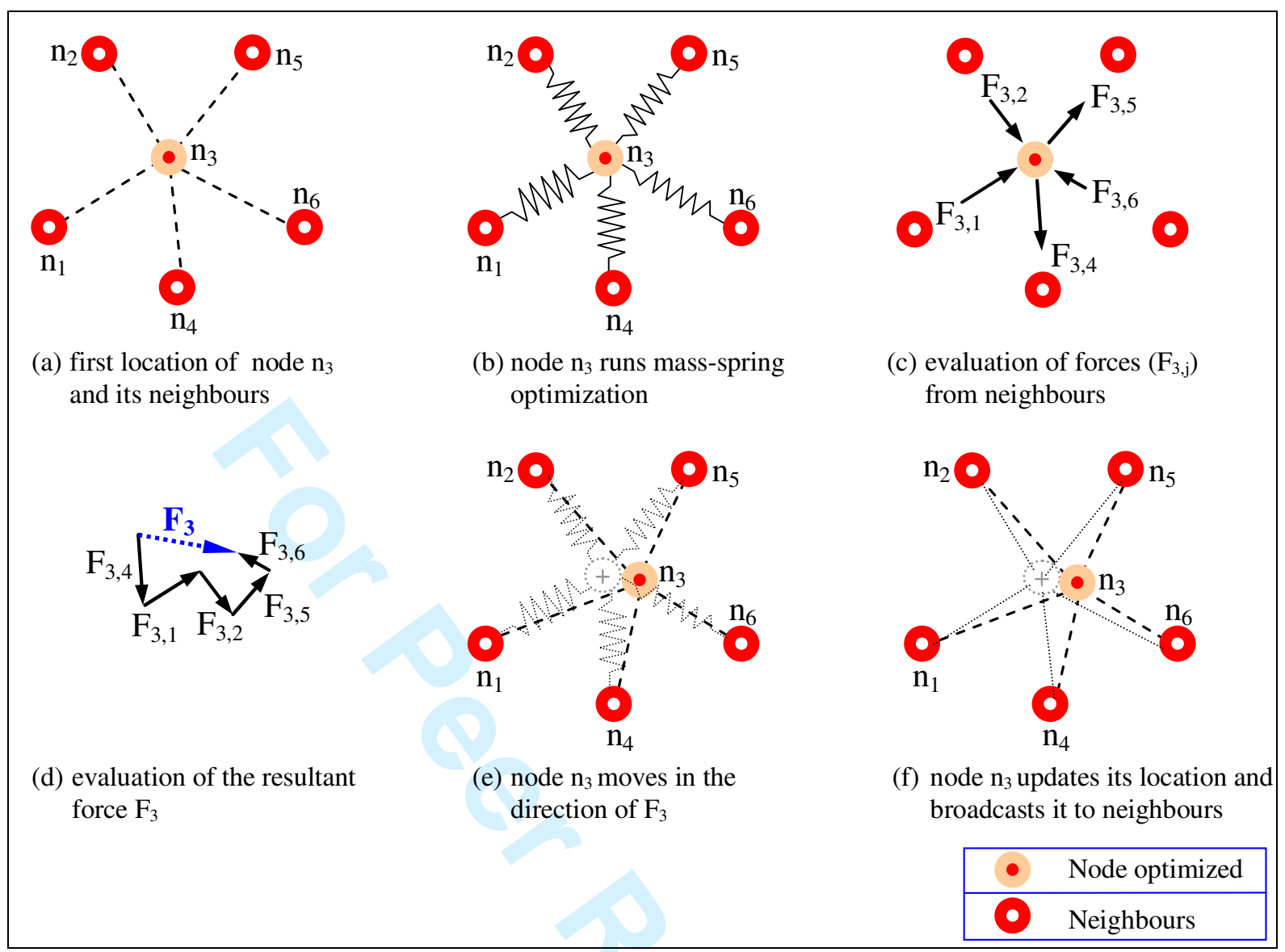

Fig. 9 - Schematic representation of AFL mass-spring optimization [Priyantha et al. - 2003]

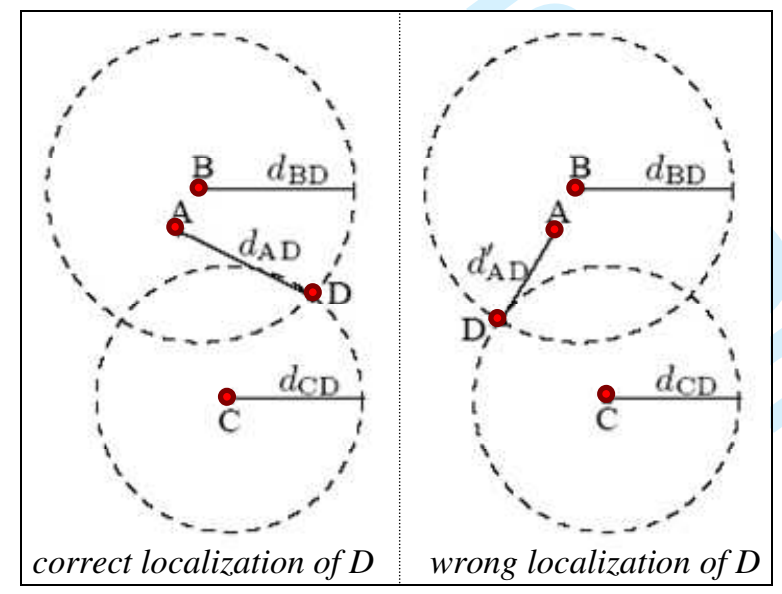

Fig. 10 - An example of ambiguity: node D is triangulated from the known positions of nodes A, B, and C. Measured distances $d_{B D}$ and $d_{C D}$ constrain the position of $D$ to the two intersections of the dashed circles. Knowing $d_{A D}$ disambiguates between these two positions for $D$, but a little noise in $d_{A D}$ (shown as $d^{\prime}{ }_{A D}$ ) can lead to a wrong location of node D. Moore $e t$ al. provide an algorithm which reduce the probability of such ambiguities [Moore, Leonard, Rus, Teller - 2004]. 


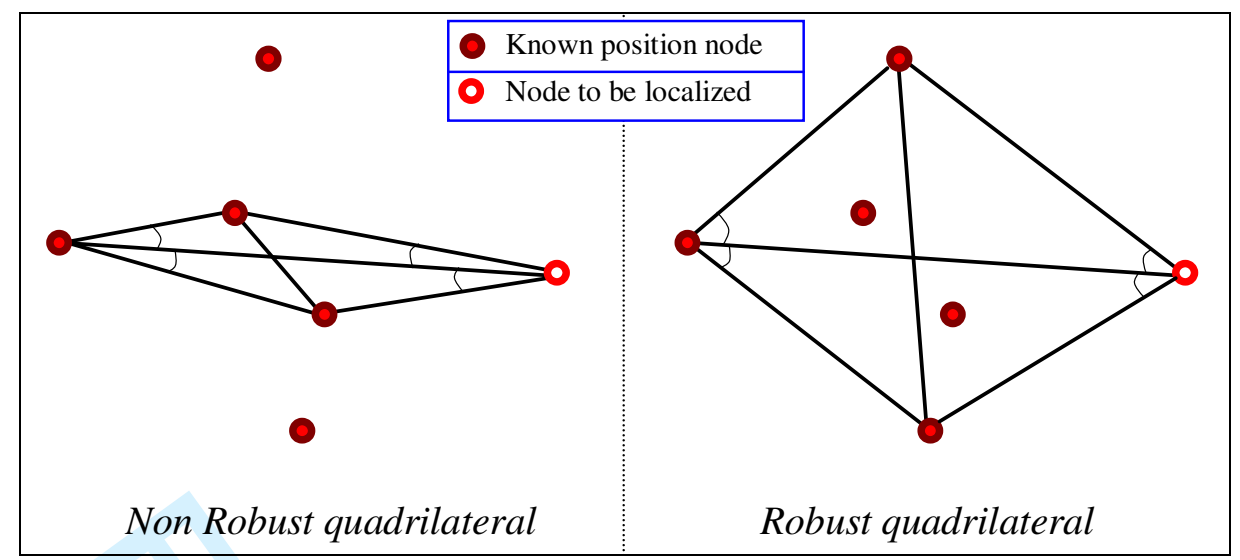

Fig. 11 - In order to prevent ambiguities, such as the one described in Fig. 10, localization is performed using robust quadrilaterals. A quadrilateral is defined robust if it is regular enough; the idea is that ambiguity occurs using "flat" quadrilaterals to solve node position [Moore, Leonard, Rus, Teller - 2004].

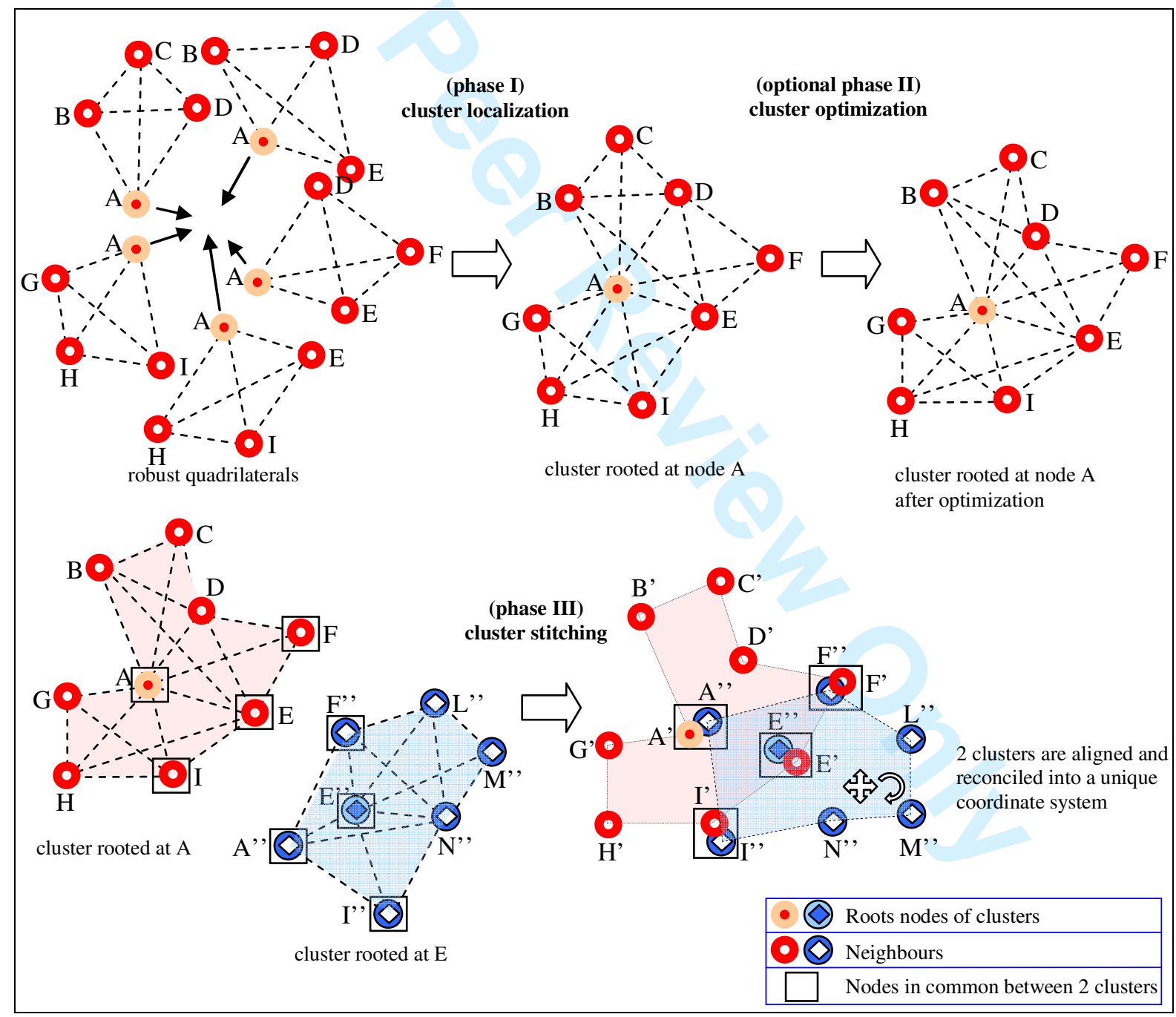

Fig. 12 - Schematic representation of Moore et al. algorithm [Moore, Leonard, Rus, Teller - 2004] 


\begin{tabular}{|c|c|c|}
\hline \multicolumn{2}{|c|}{ Criterion } & Description \\
\hline \multirow{4}{*}{$\begin{array}{l}\text { Algorithm } \\
\text { Description }\end{array}$} & Name / Acronym & Name or acronym assigned by the author(s). \\
\hline & $\begin{array}{l}\text { Author(s) and } \\
\text { Publication Date }\end{array}$ & $\begin{array}{l}\text { Author(s) name(s) and date of the algorithm } \\
\text { official release. }\end{array}$ \\
\hline & $\begin{array}{l}\text { Fine-Grained / } \\
\text { Coarse-Grained }\end{array}$ & $\begin{array}{l}\text { "Granularity" of the inter-node distance } \\
\text { estimates provided by the algorithm. }\end{array}$ \\
\hline & Short Description & $\begin{array}{l}\text { Short description of the algorithm modus } \\
\text { operandi. }\end{array}$ \\
\hline \multirow{4}{*}{$\begin{array}{l}\text { Network } \\
\text { Features }\end{array}$} & 2D/3D & $\begin{array}{l}\text { Space displacement of the sensors networks (2D } \\
\text { if nodes are coplanar, 3D if they are spatially } \\
\text { distributed). }\end{array}$ \\
\hline & $\begin{array}{l}\text { Single -Hop / } \\
\text { Multi-Hop }\end{array}$ & $\begin{array}{l}\text { In Single-Hop networks all sensors are } \\
\text { connected to each other. In Multi-Hop networks, } \\
\text { not all the sensors are directly connected. They } \\
\text { can communicate using specific routing } \\
\text { protocols. }\end{array}$ \\
\hline & Limitations & $\begin{array}{l}\text { Specific restrictions or features of the network } \\
\text { (e.g. node distribution). }\end{array}$ \\
\hline & $\begin{array}{l}\text { Anchor-Free / } \\
\text { Anchor-Based }\end{array}$ & $\begin{array}{l}\text { Anchor-Free algorithms do not require nodes } \\
\text { with pre-configured coordinates. }\end{array}$ \\
\hline \multirow{4}{*}{$\begin{array}{l}\text { Computational } \\
\text { Workload }\end{array}$} & $\begin{array}{l}\text { Data Processing } \\
\text { Description }\end{array}$ & Short description of data processing method. \\
\hline & $\begin{array}{l}\text { Centralized / } \\
\text { Distributed } \\
\text { Algorithm }\end{array}$ & $\begin{array}{l}\text { Computing is performed by a single centralized } \\
\text { node or network device, or it is equally } \\
\text { distributed among network nodes. }\end{array}$ \\
\hline & $\begin{array}{l}\text { Incremental/ } \\
\text { Concurrent } \\
\text { Algorithm }\end{array}$ & $\begin{array}{l}\text { Nodes positions are incrementally (one after the } \\
\text { other), or concurrently (parallel processing) } \\
\text { estimated. }\end{array}$ \\
\hline & $\begin{array}{l}\text { Computational } \\
\text { Complexity }\end{array}$ & $\begin{array}{l}\text { Quantitative evaluation of the time required } \\
\text { during computation. Generally, it is estimated } \\
\text { depending on number of nodes, network } \\
\text { connectivity }{ }^{1} \text {, or other network parameters. }\end{array}$ \\
\hline \multicolumn{2}{|l|}{ Benefits } & Best advantages in using the algorithm. \\
\hline \multicolumn{2}{|l|}{ Drawbacks } & $\begin{array}{l}\text { Major deficiencies and drawbacks of the } \\
\text { algorithm. }\end{array}$ \\
\hline \multicolumn{2}{|c|}{ Possible improvements } & $\begin{array}{l}\text { Possible ways of addressing the problems and } \\
\text { limitations of the algorithm. }\end{array}$ \\
\hline
\end{tabular}

Tab. 1 - Definitions and descriptions of the suggested taxonomy

\footnotetext{
${ }^{1}$ From network theory, connectivity between two nodes is defined as the number of connections (edges) in the network allowed to fail before the two nodes (vertices) become disconnected. Network connectivity is defined as the mean value of the network connectivities.
} 


\begin{tabular}{|c|c|c|c|c|c|c|c|c|c|c|c|c|c|}
\hline 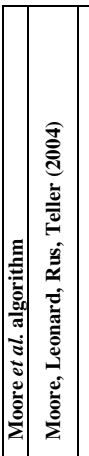 & 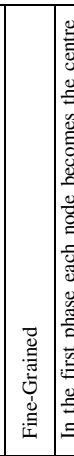 & 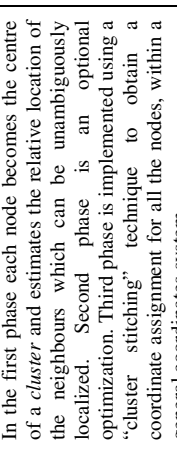 & 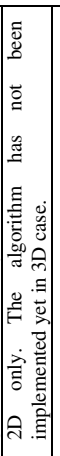 & 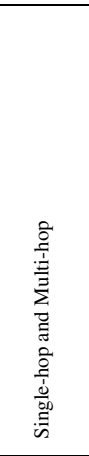 & & & 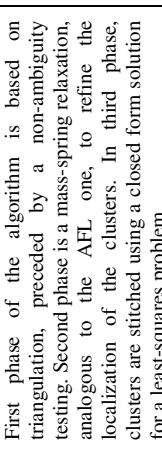 & 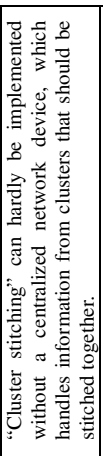 & & 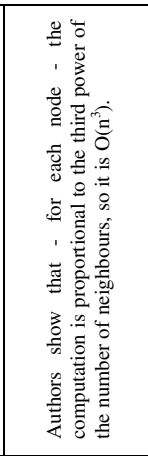 & 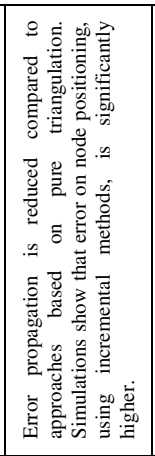 & 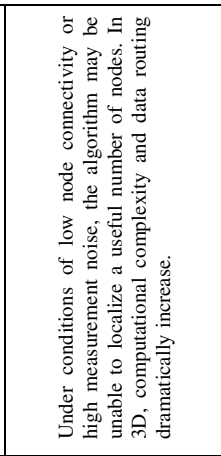 & 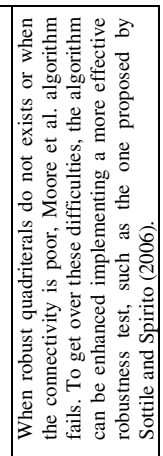 \\
\hline 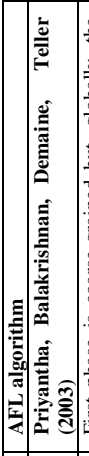 & 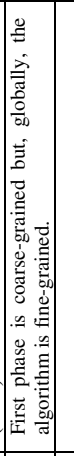 & 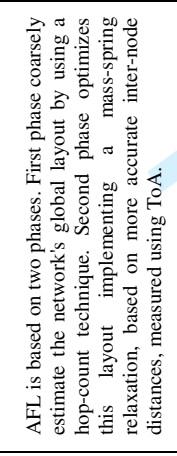 & $\begin{array}{l}\text { के } \\
\hat{\text { aे }}\end{array}$ & 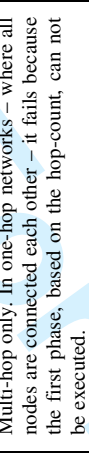 & & & 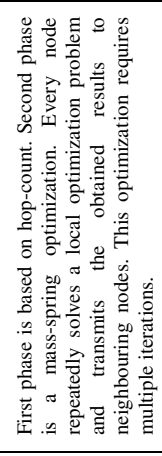 & 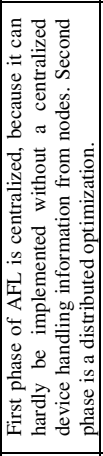 & 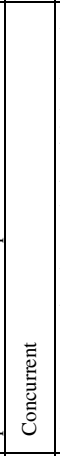 & 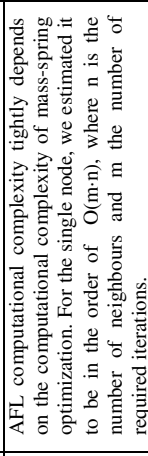 & 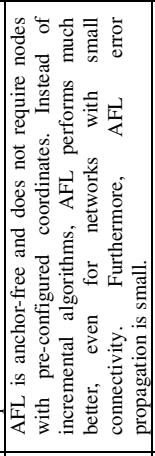 & 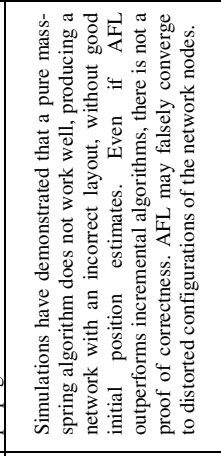 & 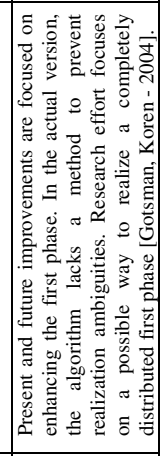 \\
\hline 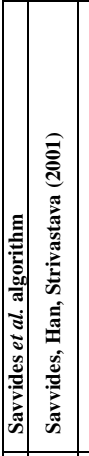 & 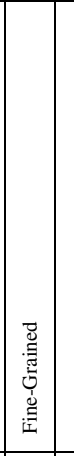 & 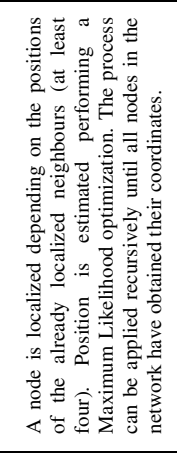 & $\begin{array}{l}\text { लि } \\
\text { बें }\end{array}$ & 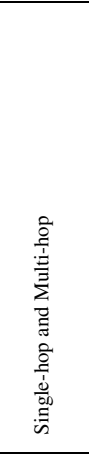 & 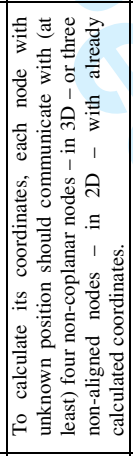 & & 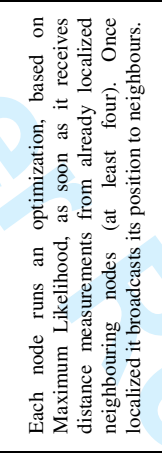 & 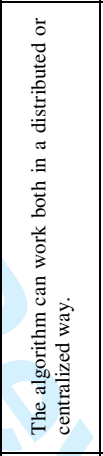 & 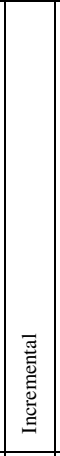 & 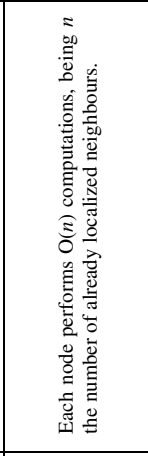 & 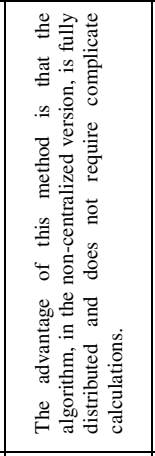 & 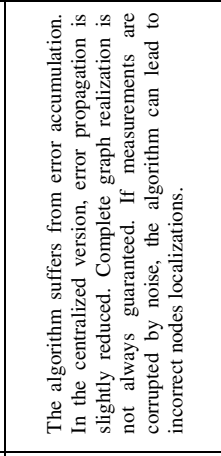 & 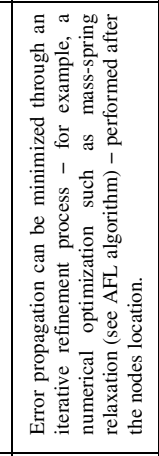 \\
\hline 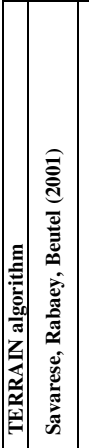 & 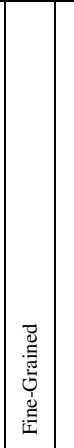 & 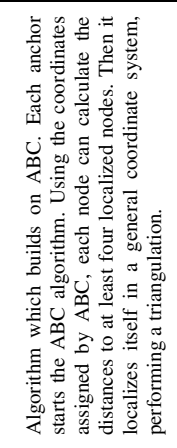 & $\begin{array}{l}\text { लि} \\
\text { तें }\end{array}$ & 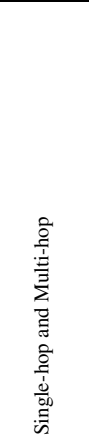 & ' & & 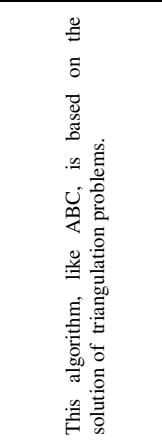 & 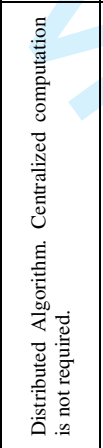 & 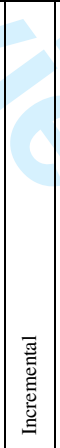 & 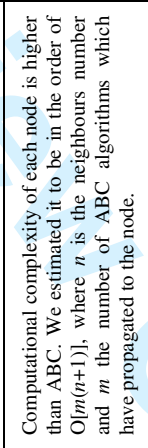 & 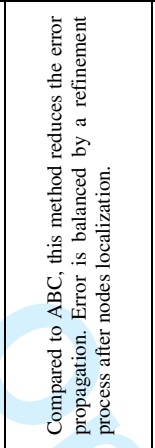 & 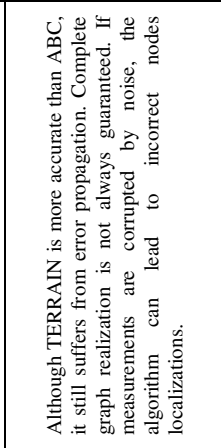 & 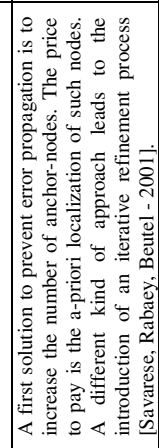 \\
\hline 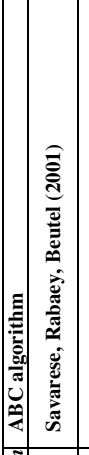 & 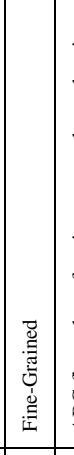 & 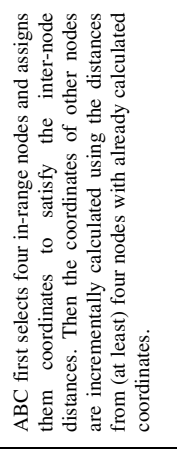 & $\begin{array}{l}\text { के } \\
\text { बें }\end{array}$ & 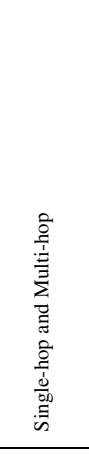 & 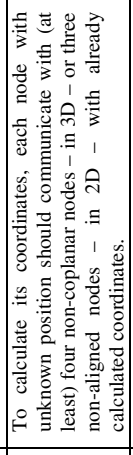 & 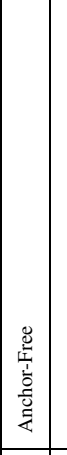 & 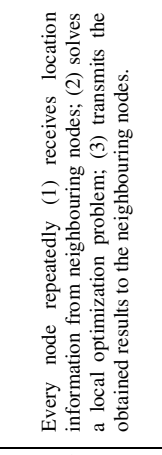 & 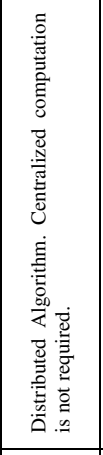 & 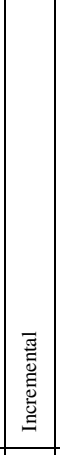 & 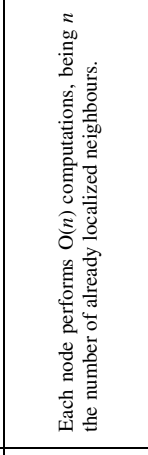 & 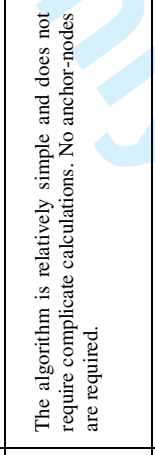 & 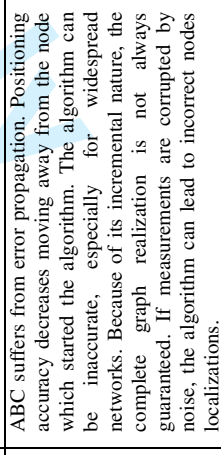 & 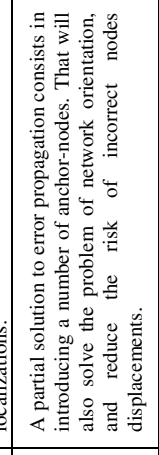 \\
\hline$\because 5$ & 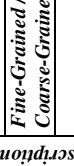 & $\hbar$ & ने & 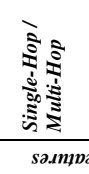 & 龍 & | & 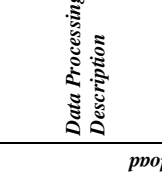 & 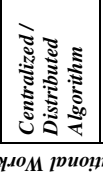 & & 言 & 气ั้ & 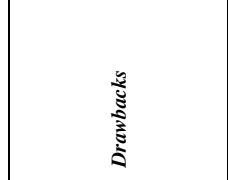 & 旁 \\
\hline
\end{tabular}

Tab. 2 - Taxonomy of localization algorithms 